\title{
UB-ALMANAC: an adaptive limit analysis NURBS-based program for the automatic assessment of partial failure mechanisms in masonry churches
}

\author{
Andrea CHIOZZI ${ }^{(1)}$, Nicola GRILLANDA ${ }^{(1)}$, Gabriele MILANI $^{*(2)}$, Antonio TRALLI $^{(1)}$ \\ (1) Department of Engineering, University of Ferrara, Via Saragat 1, 44100, Ferrara, Italy \\ (2) Department of Architecture, Built Environment \& Construction Engineering ABC, Technical \\ University of Milan, Piazza Leonardo da Vinci 32, 20133, Milan, Italy \\ * Corresponding author. E-mail: gabriele.milani@polimi.it \\ Phone: +39022399 4290 Fax: +390223994220
}

\begin{abstract}
As well known, masonry churches fail upon formation of partial failure mechanisms, usually activating at very low levels of horizontal accelerations, which are responsible for the collapse of specific macro-blocks, typically the façade, the apse, lateral naves long walls, etc. Such collapses are a sort of fingerprint for a church and are dependent on the peculiar geometric features of each structure. In order to cope with such unique behavior, the Italian Guidelines on Cultural Heritage for the safety assessment of historical masonry constructions require the separate analysis of 28 pre-assigned failure mechanisms by means of the application of the upper bound theorem of limit analysis in presence of a no-tension material. The utilization of an arbitrary subset of mechanisms, whilst fully justified by past earthquakes experience, could in principle lead to an overestimation of the load carrying capacity and force practitioners to calculations that are still not fully automated. In this context, we present here an efficient and straightforward automatic Upper Bound Adaptive LiMit ANAlysis program for masonry Churches: UB-ALMANAC. The code proposed in this paper relies into a rough finite element discretization constituted by few NURBS rigid elements joined by elasto-plastic interfaces. The mesh is directly prepared within a CAD environment based on the 3D model of the whole church, thus being immediately conceived at architectural level. Limit analysis is then performed automatically under the desired horizontal loads distribution, using the kinematic theorem of limit analysis with dissipation allowed only along interfaces and progressive adaptation of the mesh through a Genetic Algorithm, leading to a quick estimation of the first activating failure mechanism and the most vulnerable macroblock. Three small-medium size churches damaged by the recent Emilia Romagna (2012) and Monti Sibillini (2016) seismic sequences are analyzed and results are compared with both alternative numerical approaches and the actual damages observed. Very good match is systematically found, meaning that the proposed tool could represent a breakthrough towards the full automation of the limit analysis assessment of partial failure mechanisms for churches.
\end{abstract}

Keywords: Failure analysis of masonry churches; Partial failure mechanisms; FE Upper Bound Limit Analysis approach; adaptive NURBS; case studies. 


\section{Introduction}

There are more than 64,000 churches in Italy and the majority are made of masonry. As a matter of fact, all masonry structures are generally vulnerable to earthquakes, but churches in particular exhibit peculiar geometrical features that make them unsuited to withstand horizontal loads $[1,2]$. For instance, about 170 churches were damaged in occasion of the L'Aquila 2009 earthquake [3], about 500 were damaged after the Emilia 2012 earthquake (provinces of Modena, Ferrara and Bologna) [4,5], whereas more than 290 suffered more or less extended partial collapses during the more recent Amatrice 24th August 2016 earthquake.

As demonstrated by past earthquake surveys and confirmed by the last seismic sequence in the central Italy (2016), the typical failure of a church under horizontal loads occurs upon activation of partial collapses (frequently out-of-plane), even for moderate shakes. Such failure is a direct consequence of the slender perimeter walls scarcely interconnected with perpendicular ones, long and tall naves sometimes carried by slender columns (basilica shaped plant), totally inadequate interlocking between perpendicular walls, presence of flexible wooden roofs, etc. [6].

Several different strategies are adopted in the recent literature for the safety assessment of masonry churches [7], which include eigen-frequency [3,8], spectral and pushover ([9-13]) analyses, but the most suited seems still the utilization of virtual power principle with no tension materials [14].

The absence of a good global behavior suggests that the seismic vulnerability of such kind of structures may be better interpreted through the decomposition of the whole geometry into architectural portions, also known as macro-elements, each one characterized by a structural response that can be considered independent [6].

At present, the reference Guidelines to determine the seismic vulnerability of churches are undoubtedly the Italian Guidelines for the Cultural Heritage [15]. In such a code, the ultimate load carrying capacity of churches under horizontal loads is estimated using the kinematic theorem of limit 
analysis with a no-tension material model for masonry [16,17], assuming a representative subset of a priori assigned failure mechanisms.

A collection of 28 possible partial failure mechanisms (observed in occasion of past earthquakes) are catalogued in a large abacus, where the geometry is roughly idealized. Possible failure mechanisms comprise façade and tympanum overturning, apse shear and rocking failure, triumphal arch fourhinges mechanisms, etc. By means of the application of the kinematic theorem of limit analysis [16,18] the non-dimensional horizontal acceleration at collapse of the church is then associated to the identification of the failure mechanism exhibiting the lowest collapse multiplier.

Whilst such procedure is certainly appealing and straightforward, because easily applicable also by users not familiar with limit analysis concepts and earthquake engineering, it also exhibits quite relevant drawbacks. First of all, the utilization of an arbitrary subset of mechanisms, whilst fully justified by past earthquakes experience, could in principle lead to an overestimation of the load carrying capacity. In addition, designers are nowadays familiar with full 3D geometric models that fully integrate with Finite Elements (FE) codes of the whole structure by means of powerful automeshing routines whereas present limit analysis procedures on churches, proposed for example in [15], go exactly on the opposite direction, requiring hand calculations or procedures that are still far to be fully automated.

Furthermore, it should be noted that the real geometry and load conditions are roughly simplified, totally or partially neglecting some effects induced, for instance, by the presence of arches, vaults, roofs, etc., leading to undesired but necessary simplifications that keep the results obtained away from the real case. In addition, it still requires some rough assumptions on the acting loads. The collapse loads so predicted are always very conservative and much lower when compared with alternative procedures, clearly demonstrating its intrinsic limitations.

Finally, it should be pointed out that the hypothesis of no-tension material, whilst done on the safe side, totally neglects some peculiar features which may play a role at failure, such as orthotropy, limited compressive strength and shear-normal stress interaction [19]. 
The procedure based on the assumption of partial failure mechanisms is certainly almost immediate in the processing phase (application of the principle of virtual works), but needs a rather detailed and precise preparatory work of data transferring between idealized failure mechanisms and real cases, that must be repeated case by case.

In order to supersede such limitations, we present here an efficient and straightforward automatic Upper Bound Adaptive LiMit ANAlysis program for masonry Churches, also known as UBALMANAC. The code proposed, developed within MATLAB environment, relies into a rough FE discretization constituted by few Non-Uniform Rational B-Splines (NURBS) rigid elements joined by elasto-plastic interfaces, upon which an adaptive limit analysis based on the kinematic theorem is performed according to the formulation given by the Authors in [20-23]. The mesh is directly prepared in a CAD environment on the whole 3D model of the church, thus being immediately conceived at architectural level, even by unexperienced users without the advice of experts in FEs. A consistent rigid-plastic model behavior has been adopted, assuming the resistances in compression, shear and, eventually, in traction by means of a homogenization process [24,25]. Limit analysis is then performed automatically under the desired horizontal loads distribution, using the kinematic theorem of limit analysis with dissipation allowed only along interfaces. In order to reproduce exactly the active failure mechanism, a progressive adaptation of the mesh through a Genetic Algorithm (GA) [26] which moves the possible fracture lines in order to minimize the associated horizontal acceleration is performed, leading quickly to the exact determination of the first activating failure mechanism and the most vulnerable macro-block. This search is automatic; therefore, there is not an excessive overestimate of the load multiplier. Three small-medium size churches damaged by the recent Emilia Romagna (2012) and Monti Sibillini (2016) seismic sequences are analyzed and results are compared with both alternative numerical approaches and the actual damages observed. Very good match is systematically found, meaning that the proposed tool could represent a breakthrough for the full automation of churches partial failure mechanisms in a limit analysis software. 


\section{UB-ALMANAC core: NURBS FEs, Upper Bound Limit Analysis and Mesh Adaptation}

In the following sub-sections, the three main features characterizing the proposed program are briefly discussed, namely the discretization into few NURBS rigid elements, the Upper Bound Limit Analysis and the mesh adaptation scheme adopted, which follows a classic GA.

\subsection{NURBS FEs}

The analysis of the church starts with a NURBS representation of the geometry [27]. The utilization of NURBS is particularly suited for churches, where the presence of vaults, domes, arches, rose windows, semi-circular apses and curved openings needs either a very detailed discretization with standard elements or the utilization of NURBS elements. Since the aim here is to mesh an entire church with few elements, the utilization of NURBS entities seems unavoidable. In addition, UB-ALMANAC is directly interfaced with commercial CAD packages, where the description and the computation of complex geometries passes through B-Splines and NURBS approximating functions.

NURBS basis functions are built on B-splines basis functions, which are piecewise polynomial functions defined by "knots" (i.e. points in a parametric domain) $\Xi=\left\{\xi_{1}, \xi_{2}, \ldots, \xi_{n+p+1}\right\}$, where $p$ and $n$ denote the polynomial order and the total number of basis functions, respectively.

Given a set of weights $w_{i} \in \mathbb{R}$ and the $i$-th B-spline basis function $\left(N_{i, p}\right)$, then the NURBS basis function $R_{i, p}$ can be written as follows [27]:

$$
R_{i, p}(\xi)=\frac{N_{i, p}(\xi) w_{i}}{\sum_{i=1}^{n} N_{i, p}(\xi) w_{i}}
$$

NURBS basis functions have the great advantage of representing "exactly" the geometry of a wide set of curves such as circles, ellipses, and parabola, and of the surfaces that generated by these curves. A NURBS surface of degree $p$ in the $u$-direction and $q$ in the $v$-direction is a parametric surface in the three-dimensional Euclidean space defined as: 
$\mathbf{S}(u, v)=\sum_{i=0}^{n} \sum_{j=0}^{m} R_{i, j}(u, v) \mathbf{B}_{i, j}$

where $\left\{\mathbf{B}_{i j}\right\}$ form a bidirectional net of control points. A set of weights $\left\{w_{i, j}\right\}$ and two separate knot vectors in both $u$ and $v$ directions must be defined. Many commercial free form surface modelers, such as Rhinoceros ${ }^{\circledR}$, utilize NURBS representation and its properties to generate and manipulate surfaces in the three-dimensional space. In the numerical simulations presented in this paper, geometries are modeled within Rhinoceros as NURBS surfaces and the resulting NURBS structures are imported within a MATLAB ${ }^{\circledR}$ environment through the IGES (Initial Graphics Exchange Specification) standard.

Once the NURBS structure created within Rhinoceros ${ }^{\circledR}$ is transferred into MATLAB ${ }^{\circledR}$ environment, NURBS properties are manipulated to define a NURBS mesh of the masonry mid-surface, in which each element is a NURBS surface itself. Typically, the easiest way to generate a NURBS mesh on a given surface is to define a subdivision of the two-dimensional parameters space $u$ - $v$, which follows from subdividing the knot vectors in both $u$ and $v$ directions into equal intervals.

\subsection{Upper Bound Limit Analysis}

Given the NURBS model, a NURBS mesh can be defined on it. Each element of the mesh, as already stated, is generated by a NURBS surface itself and can be regarded as a rigid body. Dissipation is allowed along element edges only. In this way, element edges represent fracture lines.

Thus, the kinematics of each element is determined by the six (three translational and three rotational) generalized velocity components $\left\{u_{x}^{i}, u_{y}^{i}, u_{z}^{i}, \Phi_{x}^{i}, \Phi_{y}^{i}, \Phi_{z}^{i}\right\}$ of its center of mass $G_{i}$, expressed in a global reference system $O x y z$. Let us assume that the church is subjected to loads independent from the collapse multiplier $\lambda$ (say $\mathbf{F}_{0}$, e.g. gravity loads) and loads dependent on $\lambda$ (say $\lambda \boldsymbol{\Gamma}_{0}$, e.g. seismic action where $\Gamma_{0}$ is the so-called unitary vector of actions $\lambda$-dependent when the collapse multiplier is unitary) are present. 
A so called normalization condition - classically obtained by imposing that power dissipated by load depending on $\lambda$ is unitary when $\lambda=1$ - is needed to restrict the homothetic failure mechanisms to one. Such normalization condition can be written as follows:

$D_{\Gamma_{0}}=\Gamma_{0}^{T} \mathbf{U}=1$

Where $\mathbf{U}$ is the vector of assembled generalized velocities of the elements. Consequently, external power dissipated is the following:

$D_{e x t}=D_{F_{0}}+\lambda D_{\Gamma_{0}}=\mathbf{F}_{0}^{T} \mathbf{U}+\lambda$

Equating internal $D_{\mathrm{int}}$ and external dissipation $D_{e x t}$, in the framework of the upper bound theorem, where it is required the minimization of $\lambda$, the objective function is therefore $\lambda=D_{\text {int }}-\mathbf{F}_{0}^{T} \mathbf{U}$ and the load multiplier does not enter into independent variable of the linear programming problem.

External constraints and boundary conditions on velocities are standard and, after suitable assemblage lead to a set of equalities that can be written in compact notation as follows (see [20] for details):

$$
\mathbf{A}_{e q, \text { geom }} \mathbf{U}=\mathbf{b}_{\text {eq, geom }}
$$

where $\mathbf{A}_{\text {eq,geom }}$ is the matrix of geometric constraints and $\mathbf{b}_{e q, g e o m}$ the corresponding vector of coefficients.

Plastic compatibility constraints on interfaces are imposed on intrados and extrados, subdividing edges into $N_{s d}$ segments and $\left(N_{s d}+1\right)$ collocation points $P_{i}$, as sketched in Figure 1.

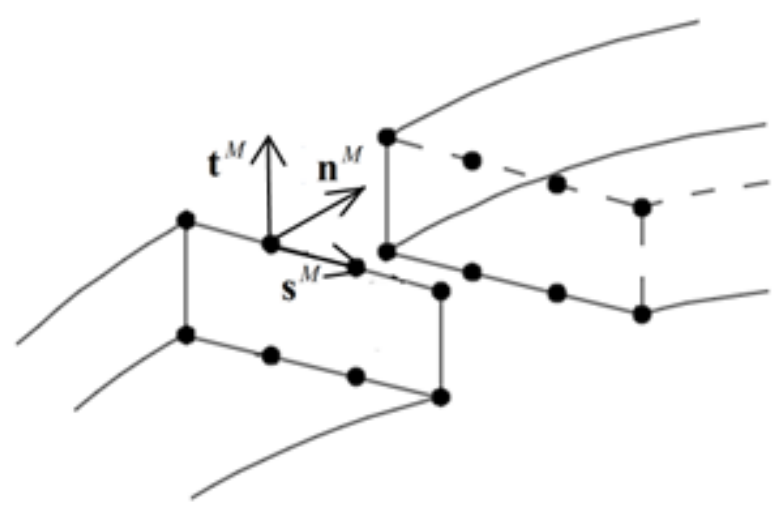

Figure 1: Masonry-masonry interface and corresponding local reference system. 
A local frame of reference $(\mathbf{n}, \mathbf{s}, \mathbf{t})$ on each $P_{i}$ is easily found according to [20] (where the reader is referred for further details), indicating with $\mathbf{n}$ the unitary vector normal to the interface, with $\mathbf{s}$ the tangential unitary vector in the longitudinal direction and with $\mathbf{t}$ the tangential unitary vector in the transversal direction. After suitable linearization of the failure surface, on $P_{i}$ the following compatibility equation must hold:

$\Delta \tilde{\mathbf{u}}=\left(\dot{\lambda}^{T} \frac{\partial f}{\partial \boldsymbol{\sigma}}\right)^{T}$

where $\boldsymbol{\sigma}=\left[\sigma_{n n}, \sigma_{n s}, \sigma_{n t}\right]^{T}$ is the stress vector acting on $P_{i}$ in the local frame of reference, $f(\boldsymbol{\sigma})$ is the linearized strength domain $\left(\frac{\partial f}{\partial \boldsymbol{\sigma}}\right.$ is therefore a three-column matrix of coefficients of the linearization plane), $\dot{\lambda}$ is the vector of non-negative plastic multiplier rates and $\Delta \tilde{\mathbf{u}}$ is a $3 \times 1$ vector of jump of velocities on $P_{i}$ written in the local frame of reference.

Internal dissipation on a single interface $i$ of area $S_{i}$ is estimated by numerical integration of collocation points as follows:

$D_{\mathrm{int}}^{i}=\int_{S_{i}} \boldsymbol{\sigma} \cdot \Delta \tilde{\mathbf{u}} d S=\int_{S_{i}} \dot{\lambda}^{T}\left(\boldsymbol{\sigma}^{T} \frac{\partial f}{\partial \boldsymbol{\sigma}}\right)^{T} d S=\int_{S_{i}} \dot{\boldsymbol{\lambda}}^{T} \mathbf{b}_{s d} d S$

Where $\mathbf{b}_{s d}$ is the column-vector of coefficients of the strength-domain linearization planes.

The obtained linear programming problem to estimate the collapse multiplier via an upper bound approach is therefore the following:

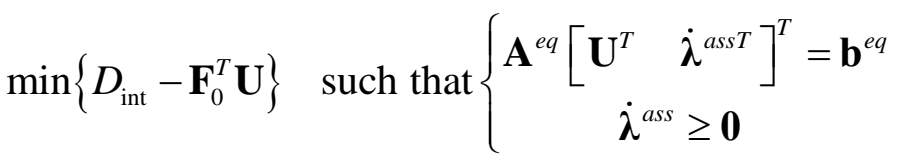

Where $\mathbf{A}^{e q}$ is the overall equality constraints matrix (with $\mathbf{b}^{e q}$ the corresponding right hand side vector) collecting plastic flow constraints on discontinuities, velocity boundary conditions and external power normalization condition and $\dot{\lambda}^{\text {ass }}$ is the assembled vector of plastic multiplier rates. The reader is referred to [28] for a critical discussion of the most efficient tools (linear and non-linear) to solve 
such optimization problem efficiently. It should be pointed out that UB-ALMANAC is also capable to deal with horizontal diaphragms if present, either by modeling them as a single NURBS surface or by introducing additional kinematic constraints between nodes placed at the diaphragm level. The presence of diaphragms obviously influences local failure mechanisms by introducing a restraint against out-of-plane overturning or expulsion. Nevertheless, this is usually not the case of masonry churches, where efficient diaphragms are seldom present.

\subsection{GA mesh adaptation scheme}

A genetic algorithm (GA) is used to adjust the mesh in order to find the minimum collapse multiplier among all possible configurations and therefore to determine the actual collapse mechanism [20]. A genetic algorithm is a method for solving both constrained and unconstrained optimization problems based on a natural selection process that mimics biological evolution. The algorithm repeatedly modifies a population of individual solutions. At each step, the genetic algorithm randomly selects individuals from the current population and uses them as parents to produce the children for the next generation. Over successive generations, the population "evolves" toward an optimal solution. In this way, it is possible to find the position of fracture lines associated to the minimum kinematic multiplier, which are the collapse mechanism and the collapse multiplier.

This procedure can be applied to the NURBS model of the whole church. In automatic way, the main structural macro-elements, such as the façade, the apse and lateral walls, form the model are provided. For each unit, an initial set of rigid NURBS elements partitioning the original geometry is identified through a suitable subdivision of the parameters space. Through the Genetic Algorithm and with a mesh composed by a strongly reduced number of elements (about 10) the most vulnerable element can be determined: it will be the local mechanism exhibiting the minimum load multiplier. After that, it is possible to accept or to modify the first solution, looking for other mechanisms on the same or on different macro-elements. 


\section{Three case studies}

The three case studies analyzed to benchmark the proposed computational tool are hereafter briefly described, focusing on some peculiar geometrical features, the damages suffered during the main seismic sequences and giving finally some historical information on the construction and the main modifications done during the centuries.

\section{- Church 1: San Giacomo Maggiore Apostolo (Pegognaga)}

San Giacomo Maggiore Apostolo in Polesine (Figure 2 and Figure 3) is a single nave structure located in Pegognaga, a small town near Mantua (northern Italy).
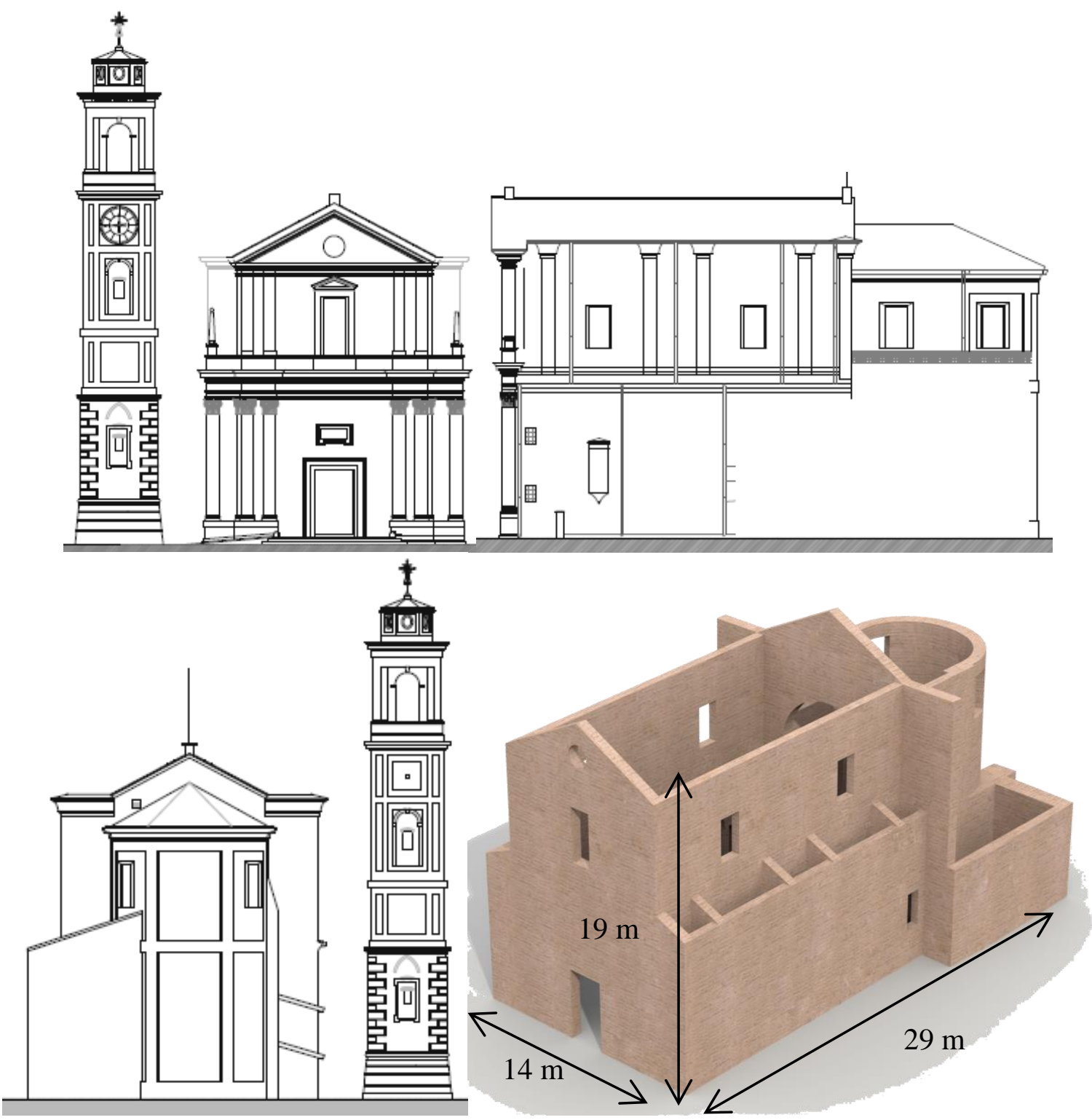

Figure 2: Church 1, San Giacomo Maggiore Apostolo in Pegognaga. From the top-left in clockwise direction: front, lateral, rear views and 3D cad rendering. 
Front, lateral and rear views of the church as it appears now, along with the 3D CAD rendering used in UB-ALMANAC are depicted in Figure 2. Some pictures of the church are provided in Figure 2(a)-(d). The church has a length of about $28.70 \mathrm{~m}$ and the single nave is 9.30 wide and approximately $18 \mathrm{~m}$ long. The presbytery is rectangular $5.80 \mathrm{~m}$ long, followed by the choir $4.60 \mathrm{~m}$ long, and ends with a circular apse. There are four lateral rectangular chapels (two per side) with internal dimensions approximately equal to $1.80 \mathrm{~m} \times 4.75 \mathrm{~m}$. The timber roof covering the nave can be structurally considered flexible. The façade, in neo-classic style, is $14.30 \mathrm{~m}$ wide and $19.20 \mathrm{~m}$ high. Internal vaults are fake and realized with reed mats plastered, with a ribbed system made of plastered wood. They are therefore not considered in the structural analyses. The bell tower is detached from the church and therefore again not considered in the limit analysis simulations. The church was built in the XV century under request of Gonzaga family, Dukes of Mantua. Several maintenance works were necessary during the centuries.

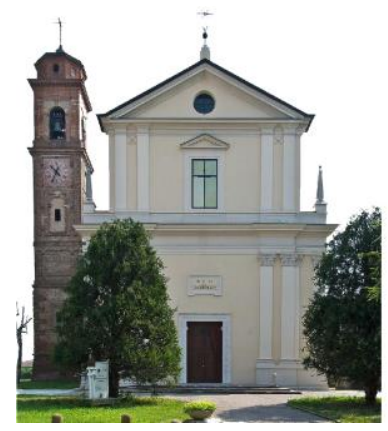

$-\mathbf{a}$

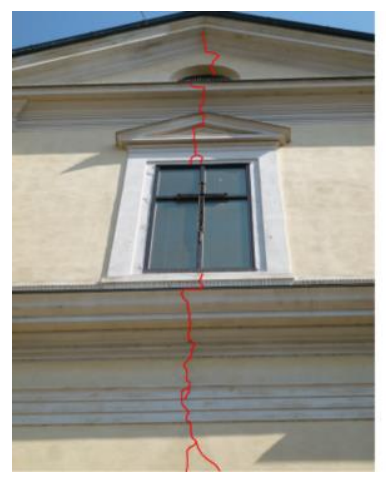

$-e$

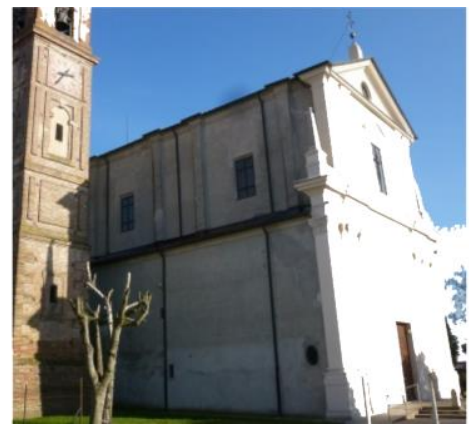

$-b$

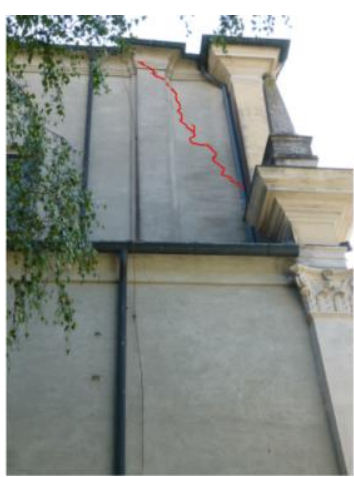

$-\mathrm{f}$

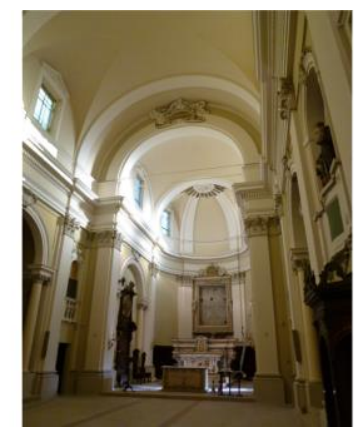

$-\mathrm{c}$

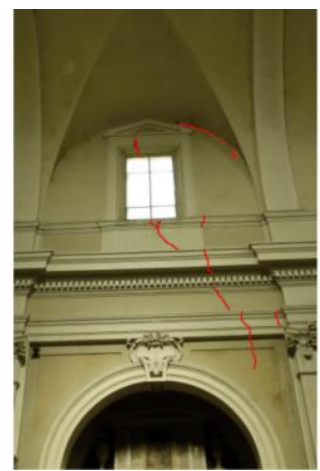

$-\mathrm{g}$

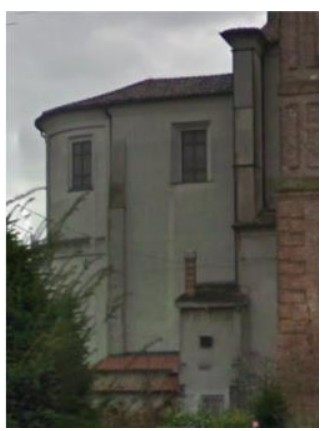

$-\mathrm{d}$

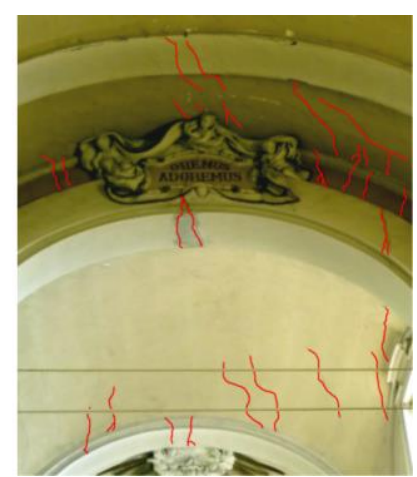

$-\mathrm{h}$

Figure 3: Church 1, San Giacomo Maggiore Apostolo in Polesine (Pegognaga).-a: façade. -b: lateral walls. $-\mathrm{c}$ : view of the presbytery. $-\mathrm{d}$ : apse. From $-\mathrm{e}$ to $-\mathrm{h}$ : damage state after the seismic event of 2012. -e: vertical crack on the façade. -f: oblique cracks near the tympanum. -g: cracks on lateral walls. -h: joints at the intrados of the triumphal arch. 
For instance, in 1746 the choir and the major chapel were restored, in the second half of ' 700 the oratory became unusable and Gonzaga family, whose political and economic power at that time was declining, could not support other renovations. As a consequence, in agreement with the Mantuan curia, the old oratory was demolished to give space to a new building.

The works for the refurbishment of the church started in 1775 and in less than one year almost all was completed, while the choir and the major chapel realized in 1746. After a stop of the restoration activity from 1776 to 1779 , the choir was demolished and rebuilt and the presbytery was finished. Lastly, in 1781 the construction of the bell started. Some renovation interventions were finally done between 1963 and 1968, as for instance the restoration of the façade.

The Emilia-Romagna (2012) seismic sequence caused to the church serious damages. A comprehensive description is provided in [5], where the reader is referred for precise details. Noticeable is the vertical fracture line on the center of the façade, cutting symmetrically the central openings, see Figure 3(e). Such crack, which is indeed a vertical yield line suggests the out-of-plane activation of a façade mechanism with partial bending strength transmitted by the perpendicular walls on vertical edges. Lateral walls present also some visible oblique fracture lines near the tympanum, Figure 3(f), which are again compatible with the overturning of the façade, with partial collaboration of perpendicular walls. There are also oblique fracture lines on the lateral walls near the opening Figure 3(g). Finally, the triumphal arch appears clearly damaged, with cracks spreading from the upper part to the intrados, Figure 3(h), indicating the formation of an in plane flexural hinge at the keystone. The church was re-opened in 2014 after several restoration interventions and seismic upgrading.

\section{- Church 2: Natività di Maria Vergine in Bondeno}

The second structure considered is a single nave church with lateral chapels (

Figure 4 and Figure 5), approximately 36 meters long and 22 meters wide. The façade is 19 meters high and is built with a typical Romanesque style. The original plant dates back to the Middle Age (1100), but exception made for the apse and the bell tower [29], the rest was re-built more recently, 
from the end of 1600 to the end of 1800 . The construction of the medieval church started in 1114, thanks to the munificent financial support of Matilde di Canossa, near a guard tower built 15 years before, which will become later the bell tower. Almost totally isolated from the church (except a very small corridor of interconnection at the ground floor level) it was readapted in XIII century, adding the belfry and partially demolishing the ancient external walls of the town. A light wooden roof carried by a curved steel truss structure (installed at the beginning of the $20^{\text {th }}$ century) covers the central nave and the chapels.
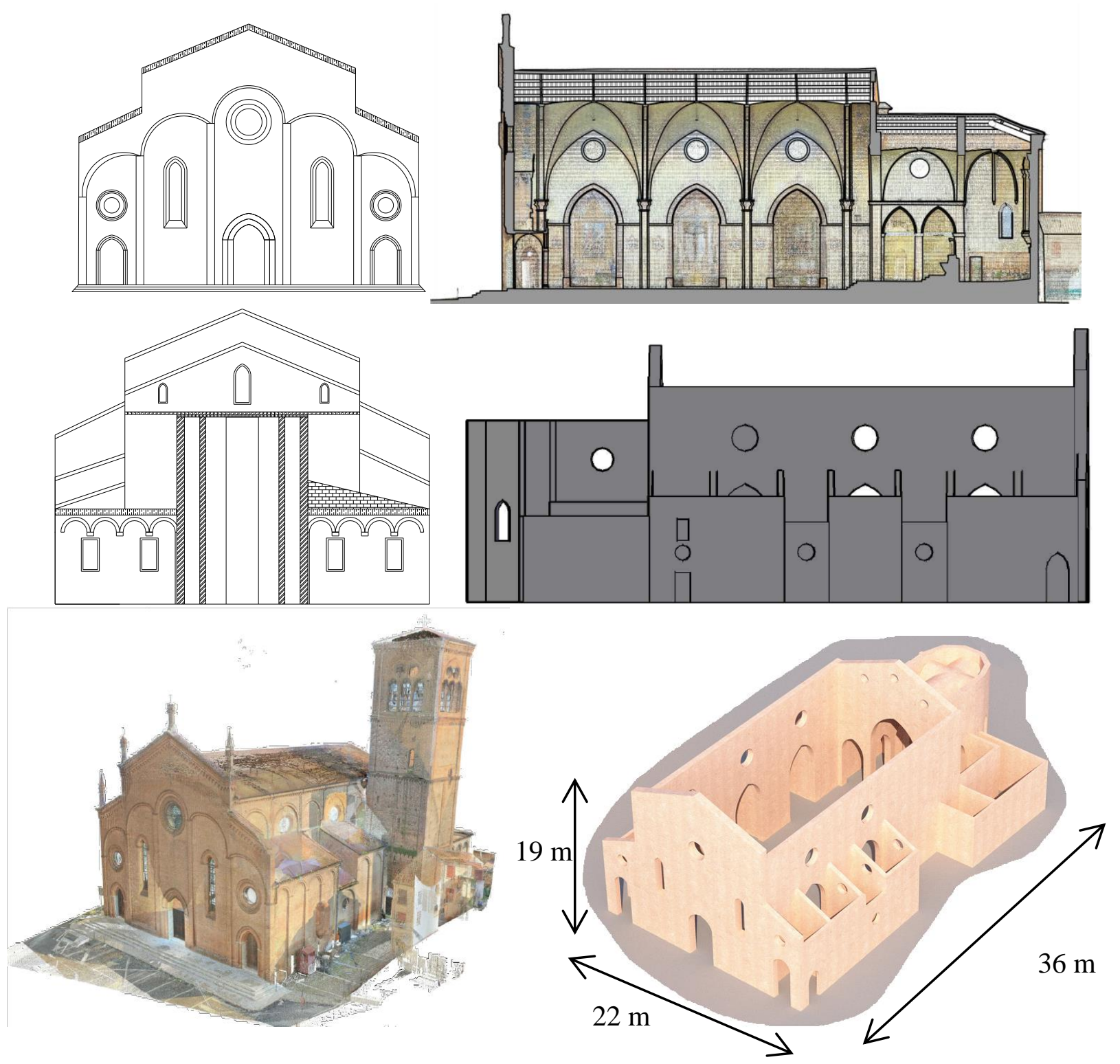

Figure 4: Church 2, Natività di Maria Vergine in Bondeno. From the top-left in clockwise direction: front view, lateral section, 3D cad rendering, 3D laser scanner model, rear view. 
The medieval semi-octagonal apse is covered by irregular ribbed gothic cross vaults, which are original of that period. Vaults are realized with thin single leaf common clay bricks. The first drawings of the façade, as it appears now with few modifications, can be found in some books printed at the end of 1600 , where the acroterial pinnacles are already visible.

The façade is characterized by three rose windows and three pointed arch doors. The nave, after a restoration intervention conducted in 1939, is equipped with a reinforced concrete ring beam visible only after inspection of the crawl space, which slightly increases the interlocking between perpendicular walls. From the single nave, the lateral chapels can be accessed by means of wide point arches. Vaults covering the nave and lateral chapels are fake and realized in plastered light wood.

The state of damage observed after the 2012 seismic sequence is the following: a partial detachment of the façade from lateral walls is visible internally, with a deep crack propagating from the bottom to the top and suggesting the overturning of the façade.
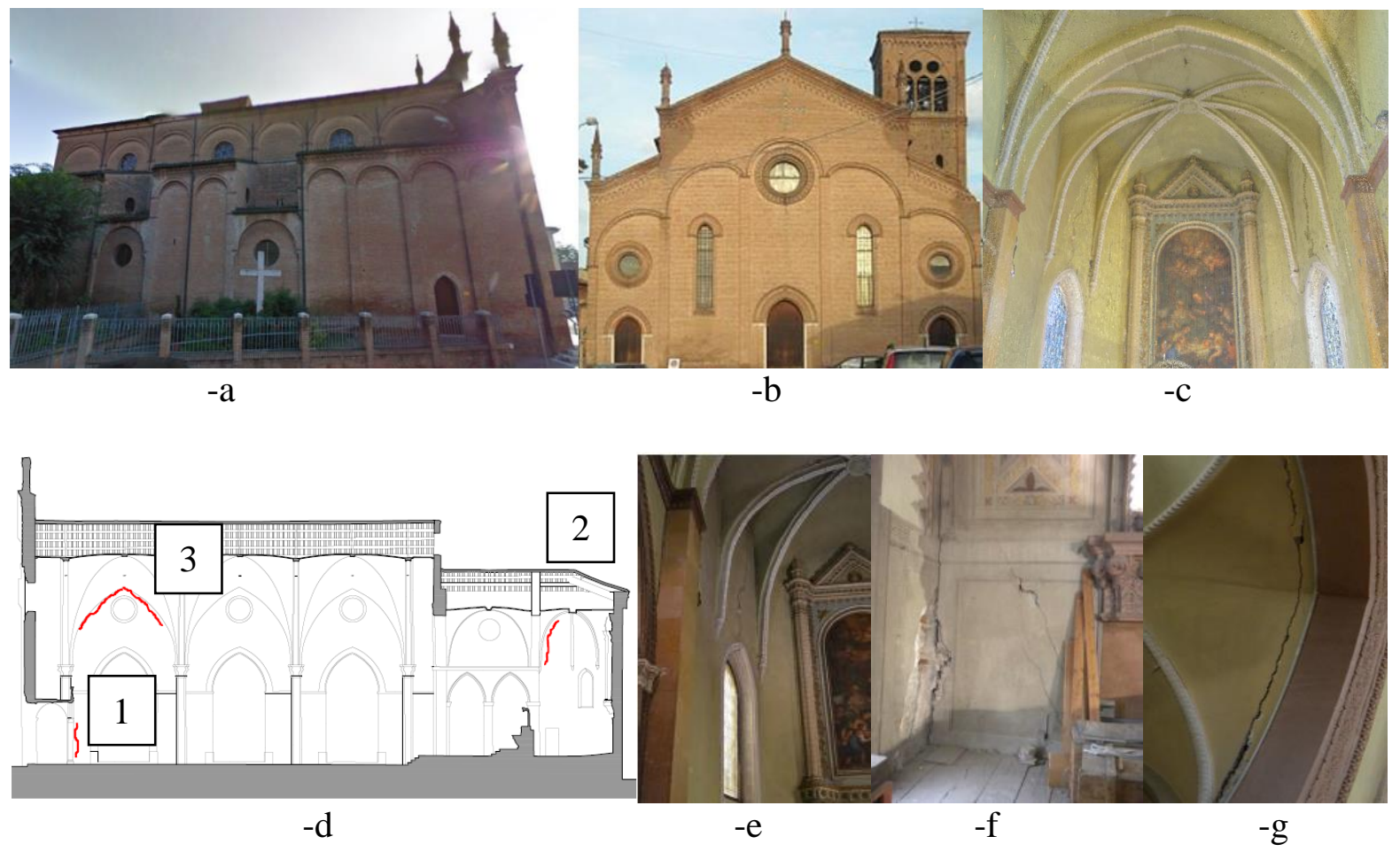

Figure 5: Church 2, Natività di Maria Vergine in Bondeno. -a: lateral phot. -b: façade photo. c: 3D laser scanner rendering of the vaulted system covering the apse, -d: longitudinal section indicating the major cracks observed. -e: cracks on the apse. $-\mathrm{f}$ : crack at the interconnection between façade and nave lateral walls. $-\mathrm{g}$ : detachment of the lateral chapels. 
Shear cracks on the apse and the vaulted system covering the apse are also quite visible. Finally, a clear detachment of some lateral chapels is observed, evidently due to the insufficient interconnection between nave walls and chapels.

\section{- Church 3: Madonna della Misericordia in Petriolo}

Church 3 (Figure 6 and Figure 8) is located in the city center of Petriolo, a small town in the central Italy (Marche region). The area is hilly, therefore some plan and profile irregularities are present, with the additional complication that in the lower part and laterally the church is in a building aggregate that would require ad hoc numerical computations able that take into account the whole compound.

Such investigation is beyond the possibilities of the present approach and this is the reason why the portion of the church indicated in red in Figure 7 is analyzed with the proposed tool. The idea to study the church as isolated is also corroborated by the damages observed after the 2016 seismic sequence. As a matter of fact, the presence of the thick and rigid floor of the church (carried by cross vaults interacting with their infill) constrained damages to spread only on the upper part.

The structure is a single nave church, the nave having a slightly trapezoidal plant 19 meters long and 11.40 wide.

The apse, constituted by five walls, has a semi-octagonal shape with dimensions $6.5 \times 9.65 \mathrm{~m}$. The total dimensions of the church in plan are therefore $11.40 \times 25.5 \mathrm{~m}$.

The works of construction started in 1496, on a pre-existing medieval church. In 1780 an extension project modified further the structure, with the elongation of 6 meters of the nave. A conservative restoration intervention was finally executed in 1920.

A barrel vault with lunettes covers the single nave in correspondence of the lateral windows, positioned on the upper part of the lateral walls, above the small chapels (two for each edge). In correspondence of the presbytery, the barrel vault ends with a semi-dome.

The bell tower has a square cross section (edge length equal to $3 \mathrm{~m}$ ) and is located in the rear part, with a small edge in common with the later wall of the nave. 


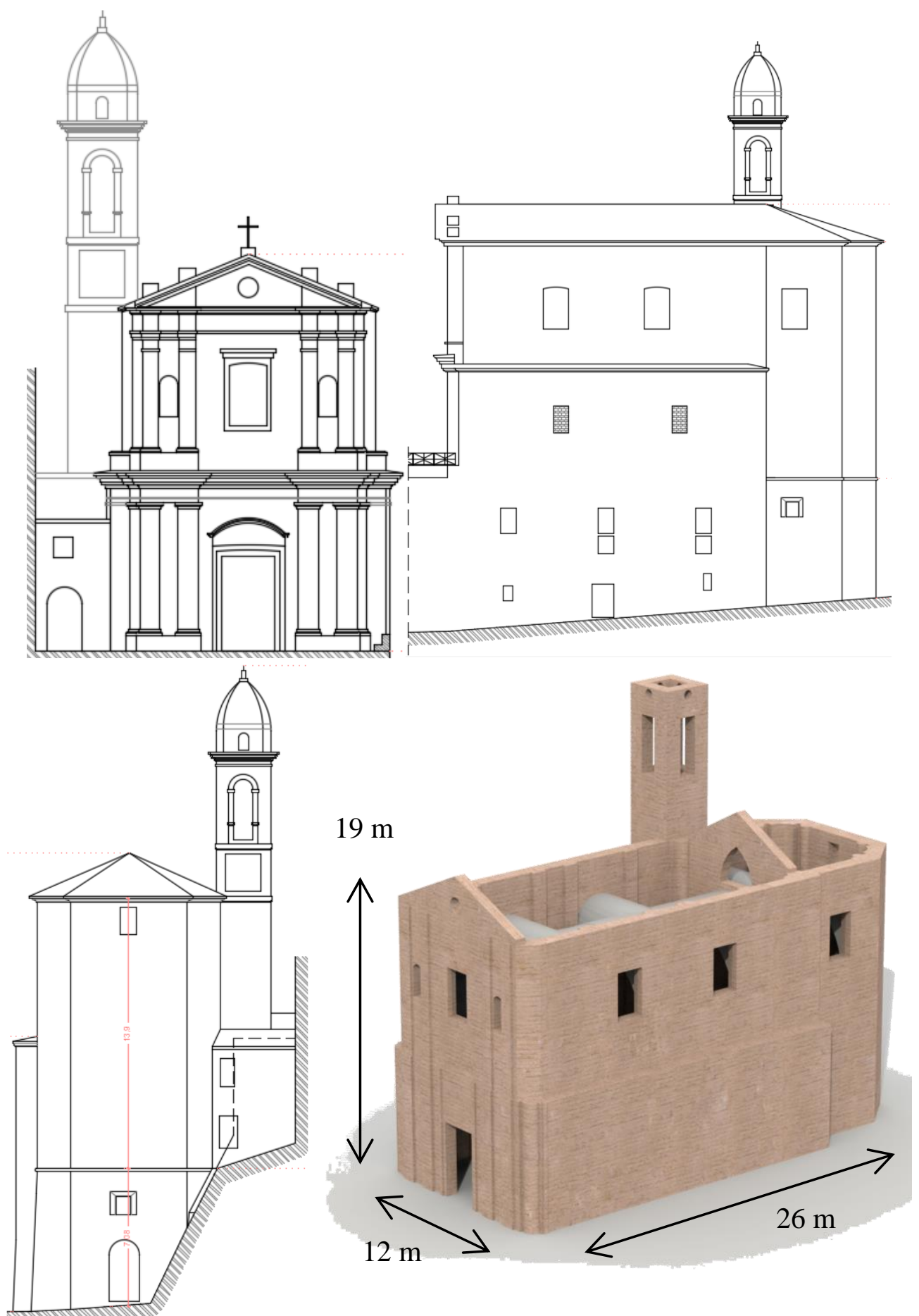

Figure 6: Church 3, Madonna della Misericordia in Petriolo. From the top-left in clockwise direction: front, lateral, rear views and 3D cad rendering.

Again, the church-tower interaction is present but not crucial and for this reason no interaction is considered for the sake of simplicity and also in partial agreement with the actual state of damage observed after the seismic sequence. The façade, made with exposed clay bricks, is $11.40 \mathrm{~m}$ wide and about $16 \mathrm{~m}$ high (top of the tympanum). 

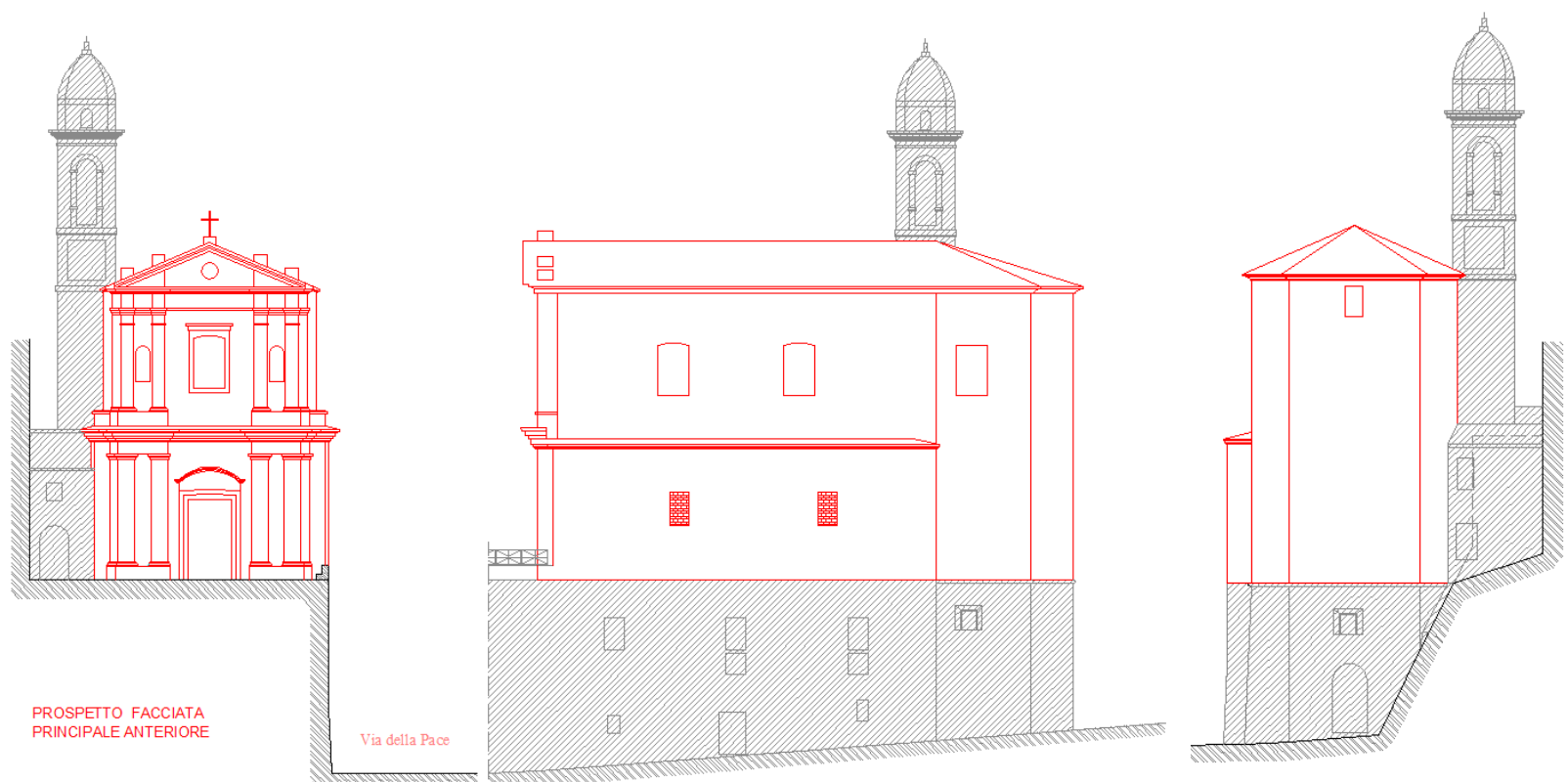

Figure 7: Church 3, Madonna della Misericordia in Petriolo. Simplified structural model adopted in the limit analysis computations.

It is characterized by the presence of four Ionic pilasters, placed symmetrically, two niches hosting statues made by a local artist, a large main entrance, a central window and a small rose window in the middle of the tympanum. It can be subdivided into three distinct portions, namely the lower part, the upper part and the tympanum. The lower part is $7.2 \mathrm{high}, 65 \mathrm{~cm}$ thick (pilaster thickness is $80 \mathrm{~cm}$ ) and the main entrance has dimensions $2.1 \times 4 \mathrm{~m}$. The upper part, $6.7 \mathrm{~m}$ high has a a smaller thickness equal to $58 \mathrm{~cm}$ (70 and $25 \mathrm{~cm}$ in correspondence of the pilasters and the niches respectively). The tympanum, with typical triangular shape is $2.2 \mathrm{~m}$ high.

Internally, a circular triumphal arch (radius $4.3 \mathrm{~m}$ ) divides the nave and the altar/presbytery. It is surmounted by a wall supporting the roof with a pointed arch opening with dimensions $2 \times 1.8 \mathrm{~m}$ (width $\mathrm{x}$ height). After the 2016 seismic sequence, several important damages were observed. In particular, the façade exhibits a deep sub-vertical crack near the axis of symmetry, involving all the façade exception made for the tympanum.

There are other two slightly eccentric inclined cracks, less visible than the central one, in the lower part, which involve both the couples of pilasters and could indicate a damage of the façade due to inplane shear. 

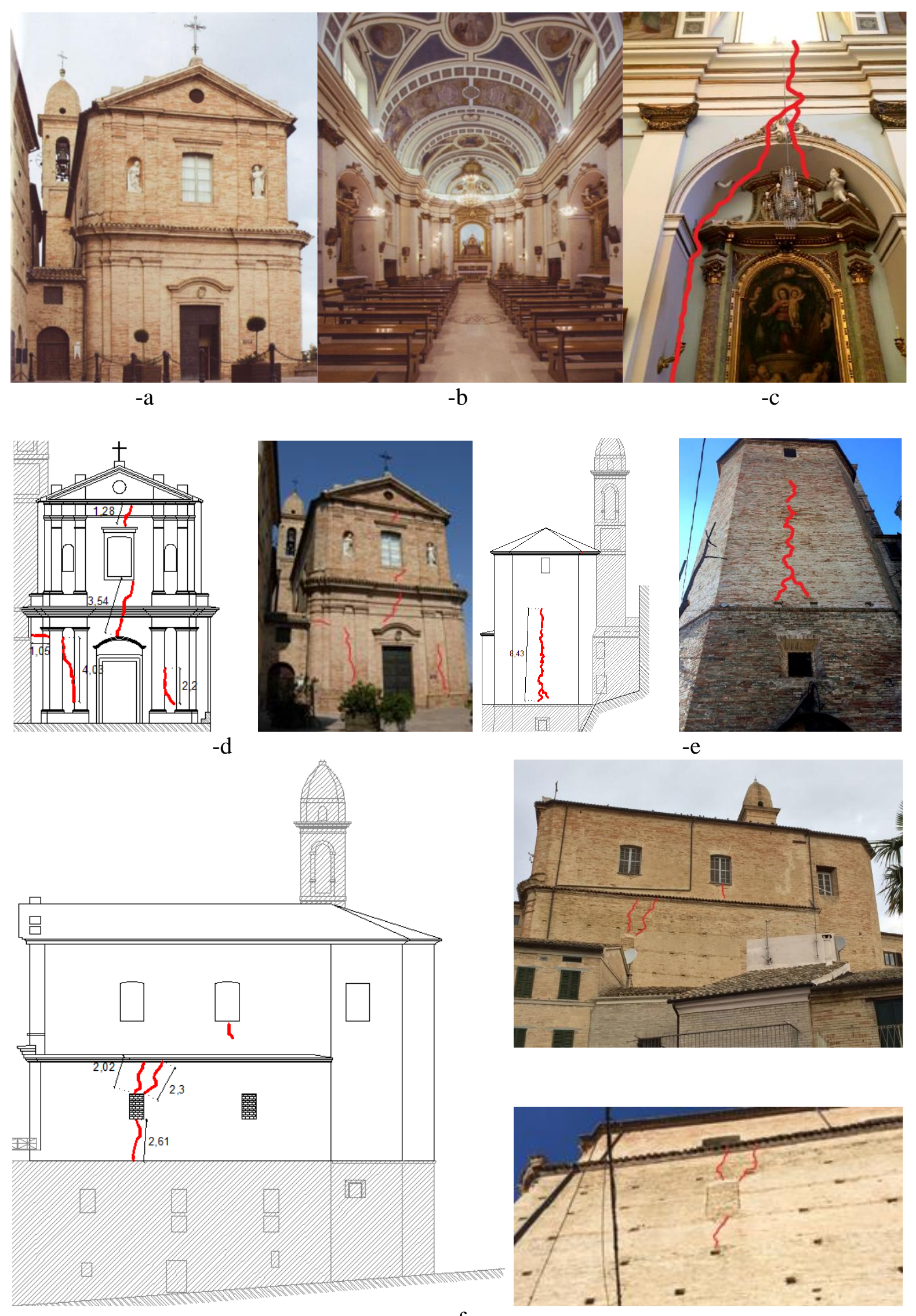

$-f$

Figure 8: Church 3, Madonna della Misericordia in Petriolo. -a: façade photo. -b: internal view. - c: deep crack on the lateral wall, from inside. - d: crack pattern on the façade. $-\mathrm{e}$ : apse vertical crack. $-\mathrm{f}$ : crack on the lateral wall, from outside. 
One of the two lateral walls of the nave exhibits a quite meaningful sub-vertical crack in the lower part, passing through the window and ending in correspondence of the cornice.

Finally, a considerable vertical crack can be noticed in the apse, in correspondence of the symmetry axis.

\section{Numerical results and comparison with existing literature}

Numerical results can be obtained with UB-ALMANAC following two different pathways, the first meshing with few NURBS the whole 3D CAD model of the church, the second just dividing the 3D model into few layers indicating the different macro-blocks as in Figure 9. The result -provided that distribution and direction of the seismic load are fixed- is the same, because the failure mechanism activating is always that associated with the minimum of the collapse multiplier, but this latter approach allows to benchmark better the program against at hand kinematic limit analysis recommended by the Italian Guidelines for the Built Heritage [15].

As a consequence, the 28 failure mechanisms suggested in [15] are assumed as reference to investigate the validity of the automatic approach proposed.

Even if homogenized failure surfaces can be used within the proposed tool in order to account for the influence of orthotropy and course orientation [20], for the sake of simplicity, masonry is here assumed as an isotropic no-tension material (i.e. setting in UB-ALMANAC a very low tensile strength to avoid numerical issues in solving the linear programming problem).

Mechanical properties for masonry have been adopted according to prescriptions contained in [30] and [31] and are reported in Table 1, for all the churches analyzed. This values have been further reduced dividing them by a confidence factor equal to 1.35 as prescribed by [30] for the cases in which limited knowledge of actual material properties is available. In the present simulations, a constant horizontal force distribution along the height of the building is assumed, as allowed by [31] (i.e. group 2 distribution, see $\$ 7.3 .4 .1$ in [31]). In UB-ALMANAC, different force distributions can be defined by the user. 


\begin{tabular}{lc}
\hline \multicolumn{2}{c}{ Masonry mechanical properties (from [30]) } \\
\hline Compressive strength $f_{\mathrm{m}}[\mathrm{MPa}]$ & 2.40 \\
Shear strength $\tau_{0}[\mathrm{MPa}]$ & 0.06 \\
Tensile strength $f_{\mathrm{t}}[\mathrm{MPA}]$ & $\approx 0$ \\
\hline
\end{tabular}

Table 1. Masonry mechanical parameters adopted in the simulations.

Finally, a very coarse NURBS mesh can be utilized in order to detect the activating failure mechanisms. The meaning of the symbols used in Figure 9 is the following:

- FA refers to façade out-of-plane mechanism. The out-of-plane mechanism with weak interlocking (FA1) with perpendicular walls is characterized always by the formation of a cylindrical hinge at the base and in this regard is uninteresting for UB-ALMANAC. As a matter of fact, the collapse acceleration is always very low and roughly equal to the ratio between thickness and height of the block subjected to overturning. More interesting is the hypothesis of good interlocking (FA2), which results obviously in an increase of the load carrying capacity. Good interlocking can be accounted for either by avoiding active element interfaces placed along the intersection between perpendicular walls or by placing, along intersections between perpendicular walls, active interfaces characterized by suitably high mechanical strength parameters. Indeed, the program is able to adjust automatically the position and inclination of the active yield lines (which correspond to the active edges of the NURBS mesh) to minimize the collapse acceleration, thus finding the actual failure mechanism.

- T stands for tympanum overturning. The mechanism with horizontal hinge at the base of the tympanum (T1) is again relatively trivial and, if the tympanum is small, generally provides fairly high collapse accelerations. The second is with inclined yield lines (T2), it is used also for the collapse of the upper part of the triumphal arch (TA) and needs again an optimization of the crack pattern configuration, which is again possible only with the procedure proposed. 


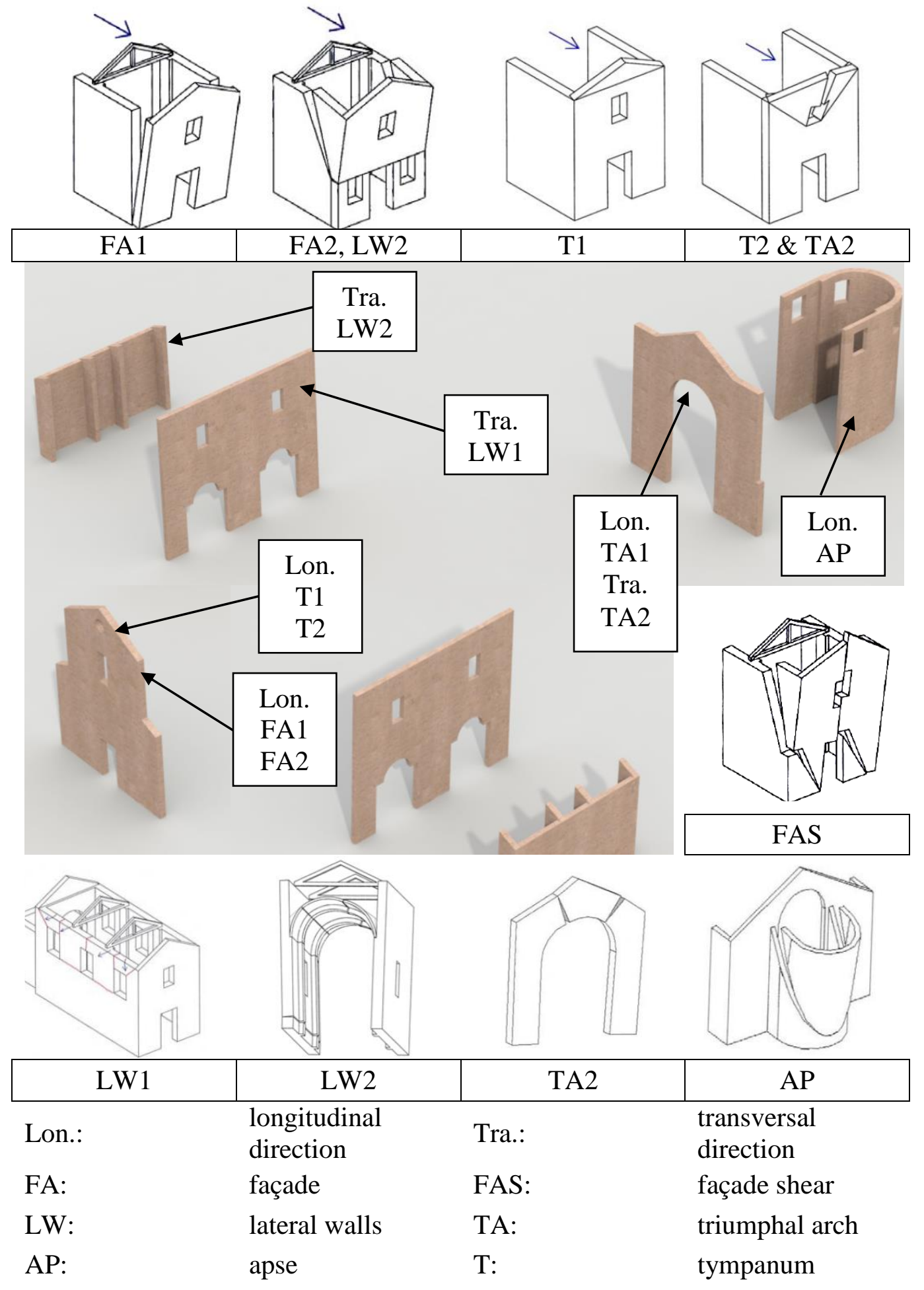

Figure 9: subdivision of the church into macro-elements and corresponding failure mechanisms suggested by the Italian Guidelines [15].

- FAS refers to an in-plane shear failure of the façade. Such mechanisms family is usually characterized by quite high collapse accelerations, but it is rather interesting because the actual 
collapse crack pattern turns out to be strongly dependent on the geometry of the façade (e.g. the shape and the position of the openings).

- LA is related to transversal lateral walls failure. More in general, we indicate with LA all those out-of-plane mechanisms involving also lateral chapels, both in absence or presence of good interlocking. When failure interests the upper part of the lateral walls of a nave, which are almost always well interconnected on vertical edges, the estimation of the correct shape of the mechanism is a tricky but key issue, which can be easily handled with the automatic procedure proposed in this paper. The same concepts may be repeated more or less identical for lateral chapels with good interlocking with perpendicular walls, i.e. when the stabilizing effect of the portion of perpendicular walls forming the mechanism is crucially determined by the inclination of the yield lines.

- TA refers to the triumphal arch behavior, with the in-plane failure for the formation of a four hinges mechanism, or the out-of-plane overturning, characterized by the formation of inclined yield lines. In both cases, the knowledge of the correct position and inclination of the yield line forming the mechanisms is a key issue for a reliable estimation of the load carrying capacity. In this context, the proposed program may represent an essential tool for the practitioner, not only for the safety assessment but also for a correct design of the strengthening intervention to implement in a vulnerability reduction framework.

- AP refers to the overturning and/or shear failure of the apse. Apse collapse is always characterized by the formation of shear cracks (more precisely on the presbytery walls) and overturning of portions of the apse as such. The evaluation of the real crack pattern activating is a quite complex task, which becomes even more difficult when the apse is covered by vaults, as in the case of Church 2. In this regard, the utilization of the proposed tool is extremely advantageous, because hand calculations are affected by a quite relevant level of approximation that could be responsible for a strong miscalculation of the collapse multiplier. 
The resultant failure mechanisms according to the proposed program (subdividing the church as in Figure 9) are depicted from Figure 10 (Church 1) to Figure 12 (Church 3). In the same figures, for the sake of completeness, values of $\alpha_{0}$ and $\boldsymbol{a}_{0}^{*}$ are also reported, where $\alpha_{0}$ is the collapse acceleration from limit analysis (normalized against $\mathrm{g}$ ) and $\boldsymbol{a}_{0}^{*}$ the corresponding spectral acceleration.

Histograms of the collapse accelerations found for the different macro-elements are depicted in Figure 13, Figure 14 and Figure 15 respectively for Church 1, 2 and 3. Blue and yellow bars refer to partial failure mechanisms evaluated through manual limit analysis and by means of the present automatic approach respectively.

As can be noted, generally there is agreement (as expected) between the two methods for weak interlocking, because the failure mechanism is trivial and can be predicted manually in an easy way.

More intriguing are all those cases where the mechanism is non-trivial (for the complexity of the geometry, like in the apse, or for the presence of cross vaults or a good interlocking on vertical edges, which turns out to involve in the mechanism a portion of perpendicular walls to be quantified). In all the aforementioned cases, sometimes some discrepancies between manual calculation and the present approach are worth mentioning, but such an outcome can be justified recalling the intrinsic limitations of hand calculations, where i.e. the choice of the mechanism is arbitrary.

In addition, it is worth noting that at-hand kinematic limit analysis based on failure mechanisms with weak interlocking between perpendicular walls is always associated with very low accelerations at failure. This is obviously a consequence of the assumption made for the masonry constitutive behavior (no tension material) as well as of the conservative hypothesis of bad interlocking between perpendicular walls (especially for the façade behavior). Nevertheless, the latter assumption appears too conservative for practical purposes and there is the risk to provide results with little match with the actual behavior of such kind of structures. The hypothesis of better interlocking certainly helps in increasing the load carrying capacity, but reliable hand calculations are difficult to perform, because the shape of the macro-elements involved in the formation of the mechanism (or better position and inclination of the active yield lines) is a priori unknown. The proposed tool, in this regard, appears 
very promising because it may efficiently furnish mechanisms that potentially are more in agreement with the real behavior of the structure, as shown by the satisfactory prediction of the real crack patterns observed.

The accelerations at failure obtained from UB-ALMANAC are hence almost systematically larger than those provided by hand calculations. This is certainly a consequence of the small but not vanishing tensile strength assumed for masonry in the code but, most importantly, the unavoidable simplifications in the geometry and load conditions may play a significant role.

As far as a comparison between the active mechanisms predicted by UB-ALMANAC and real crack patters is concerned, the following considerations may be drawn case by case:

- Church 1: a total number of 7 NURBS surfaces and 24 elements have been defined. Aassuming that the seismic load acts longitudinally, UB-ALMANAC predicts a failure for overturning of the upper part of the façade, with involvement of a portion of the perpendicular walls. The predicted overturning occurs with a horizontal hinge located near the middle height, see Figure 10. Such outcome seems partially compatible with the inclined cracks observed in the surveys, see Figure 3-f.

The vertical crack passing through the symmetry axis of the façade is obviously hardily reproducible in such a mechanism, but it can be explained as a consequence of a seismic component acting along the perpendicular direction of the church. Transversal failure of the upper part of the lateral walls does not occur in reality, not only for the actual direction of the horizontal loads, but also for the higher acceleration associated with such mechanism. Some cracks are however present in the lateral walls and in the triumphal arch, see Figure 3-g and h, which could justify the presence of a non-negligible seismic load acting transversally. Both mechanisms are characterized by slightly higher collapse accelerations than that of the façade. Similar failure loads are found investigating the apse overturning, which however appeared almost intact during the surveys. 
Façade, out-of-plane, weak connect. Façade, out-of-plane, good connect.
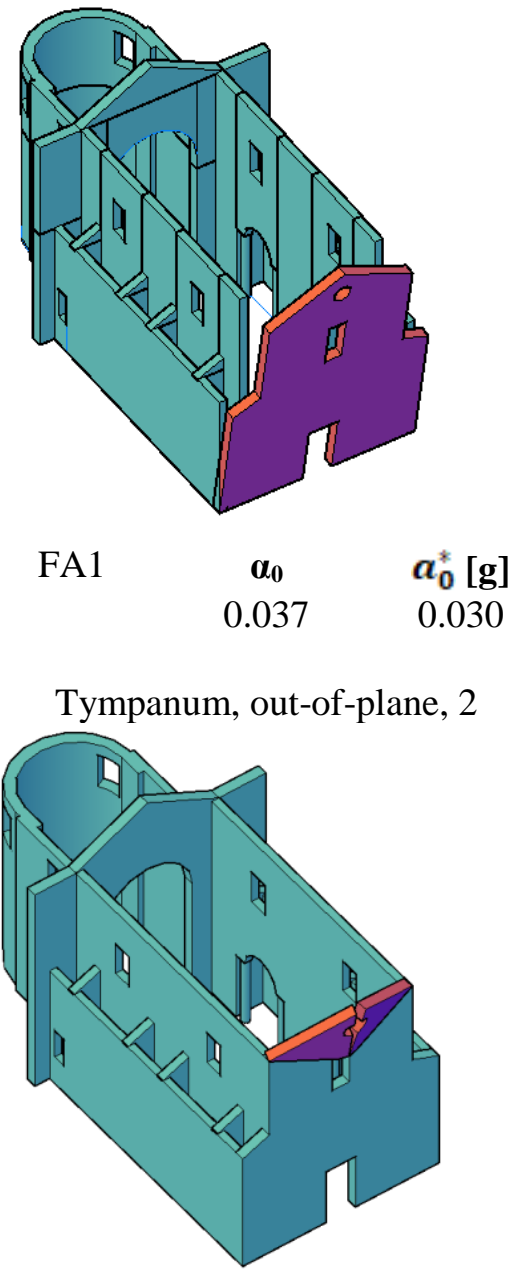

$\mathrm{T} 2$

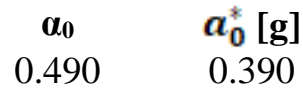

Apse

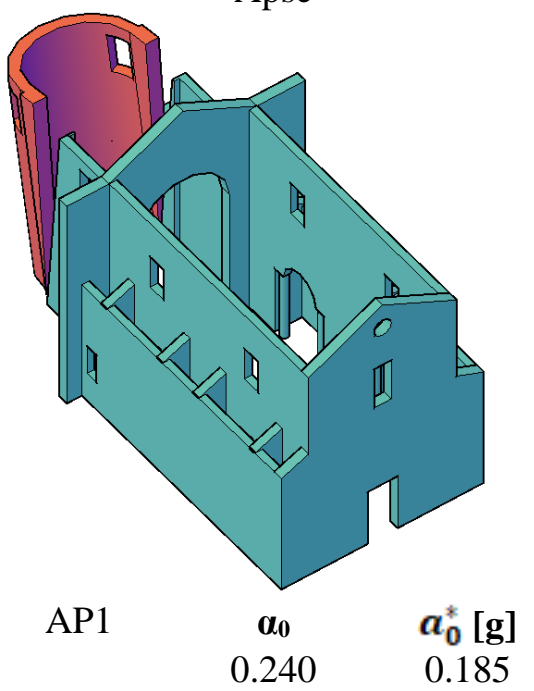

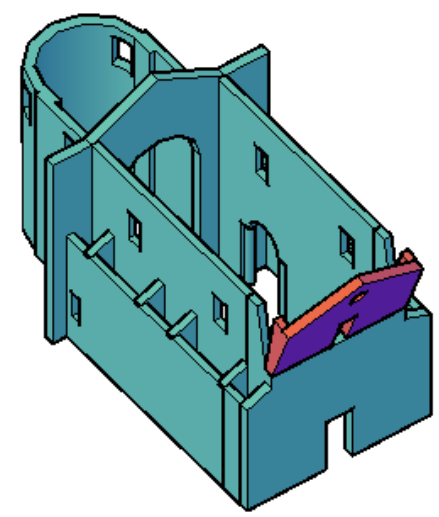

FA2

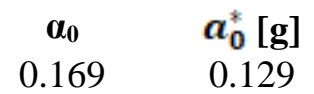

Tryumphal arch, out-of-plane

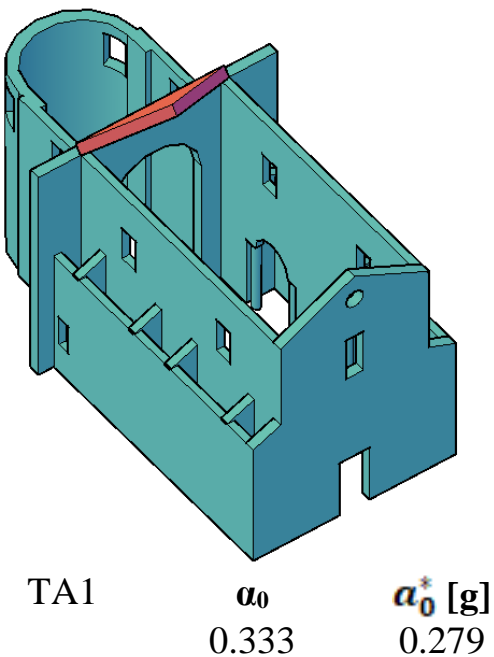

Lateral walls 1, out-of-plane

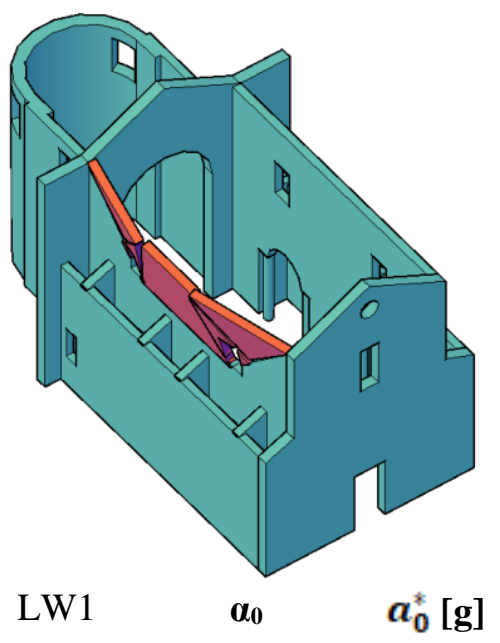

$0.242 \quad 0.203$
Tympanum, out-of-plane, 1

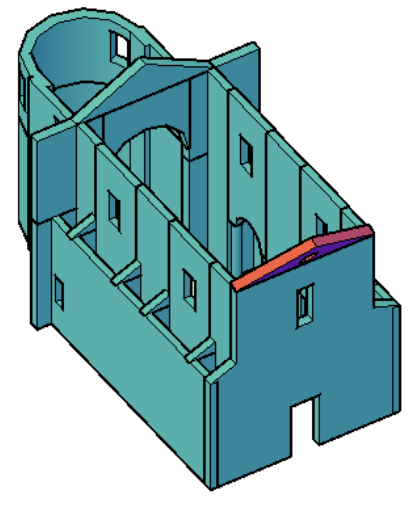

$\mathrm{T} 1$

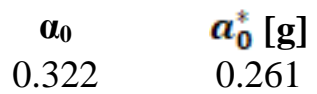

Tryumphal arch, in-plane

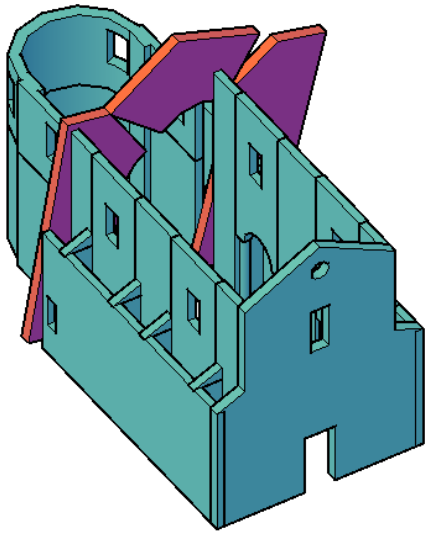

TA2

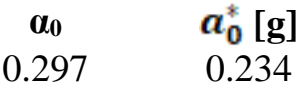

Lateral Walls 2, out-of-plane

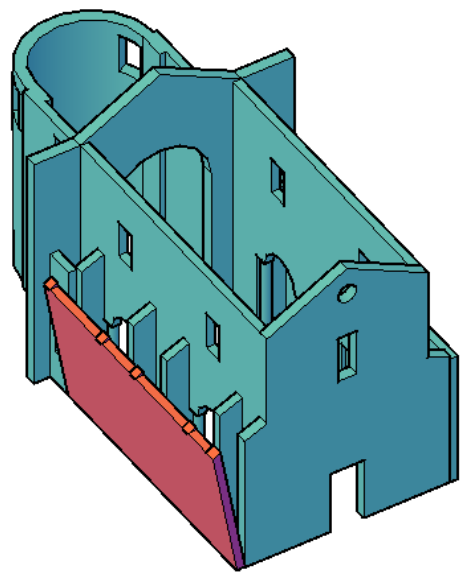

LW2

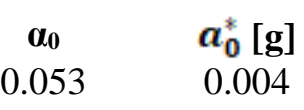

Figure 10: Church 1, San Giacomo Maggiore Apostolo in Polesine (Pegognaga). Failure mechanisms obtained with UB-ALMANAC assuming different meshes, directions of the seismic load and interconnection of the walls. $\boldsymbol{\alpha}_{0}$ is the collapse acceleration from limit analysis (normalized against $\mathrm{g}$ ) and $\boldsymbol{a}_{0}^{*}$ the corresponding spectral acceleration. 
Façade, out-of-plane, weak connect. Façade, out-of-plane, good connect.

\section{Tympanum, out-of-plane, 1}
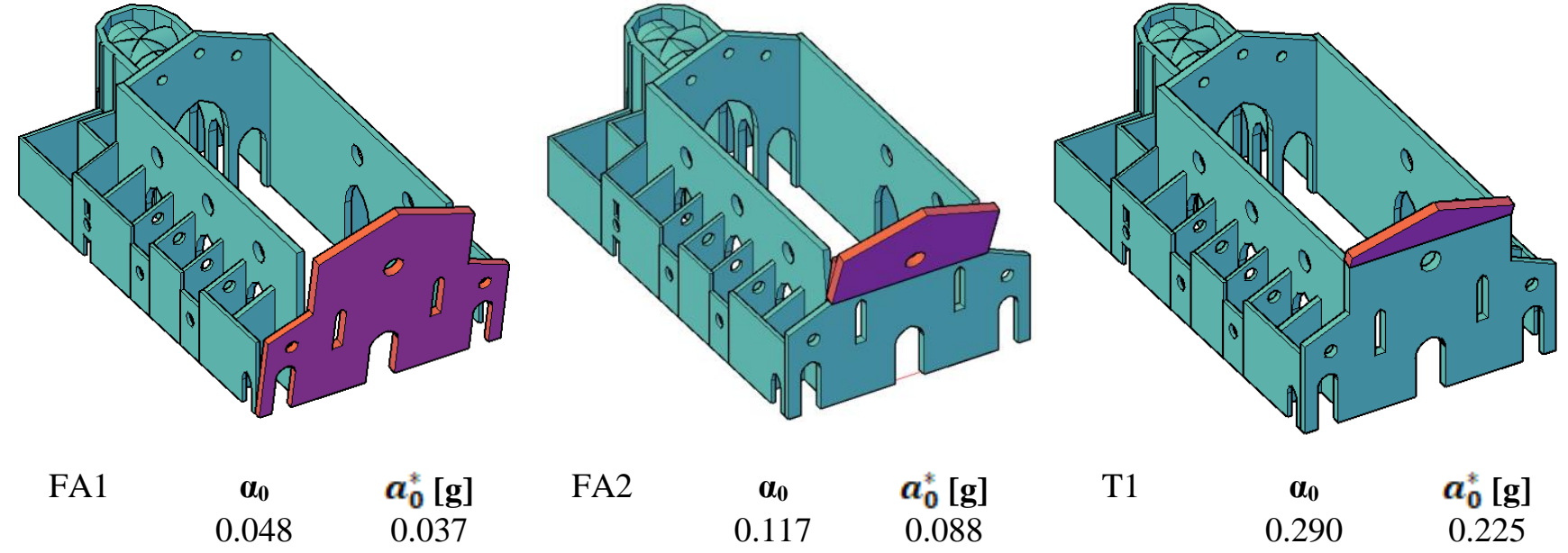

$\mathrm{T} 1$

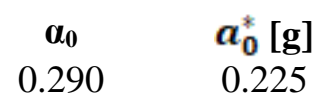

Tympanum, out-of-plane, 2
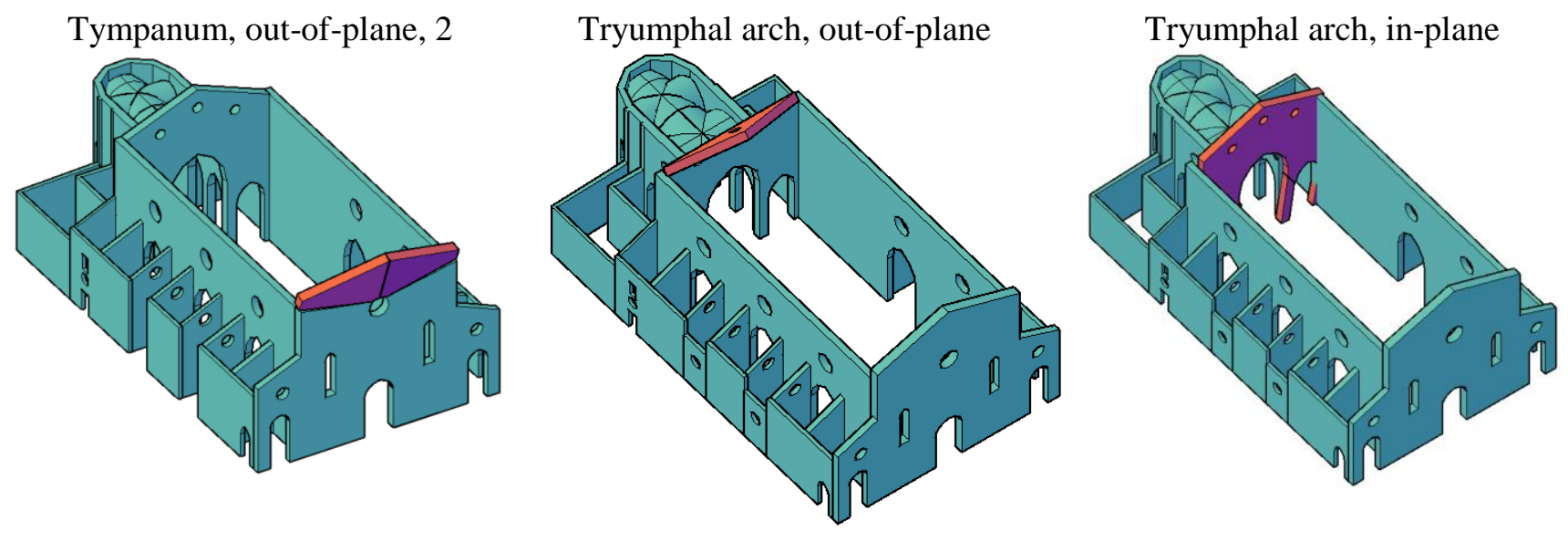

$\mathrm{T} 2$

$\begin{array}{cc}\boldsymbol{\alpha}_{0} & \boldsymbol{a}_{0}^{*}[\mathbf{g}] \\ 0.357 & 0.276\end{array}$

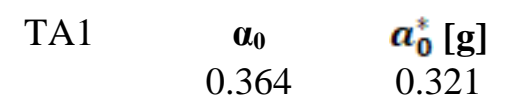

TA2

$\boldsymbol{\alpha}_{0}$

$a_{0}^{*}[\mathrm{~g}]$

0.153

0.116

Apse

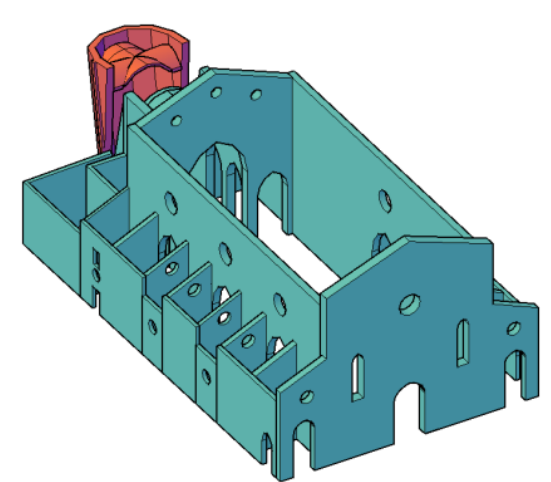

Lateral Walls 1, out-of-plane

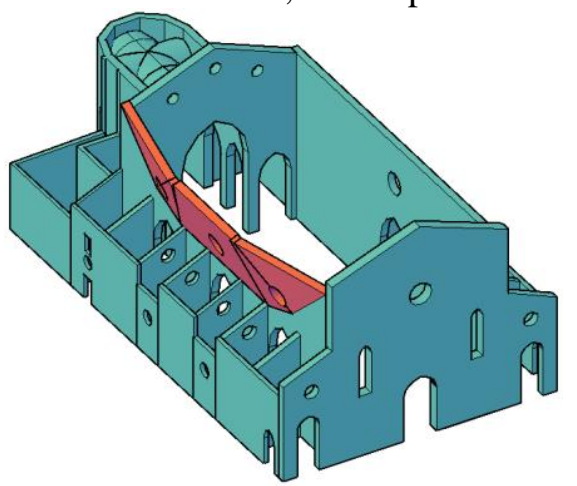

Lateral Walls 2, out-of-plane

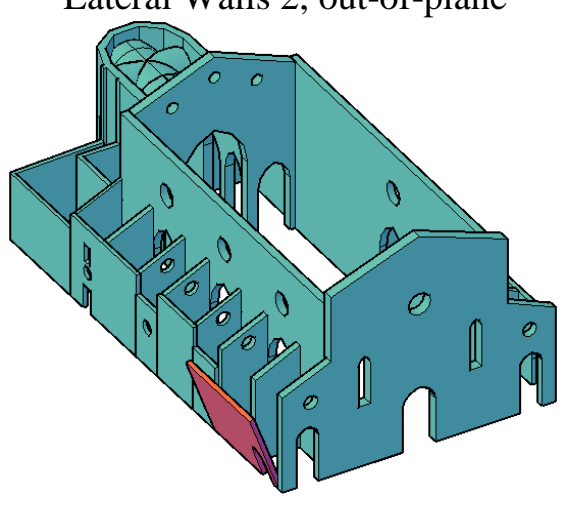

AP1

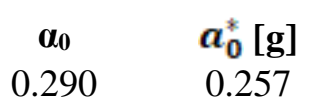

LW1

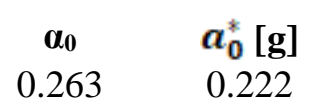

LW2

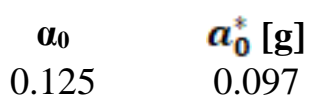

Figure 11: Church 2, Natività di Maria Vergine in Bondeno. Failure mechanisms obtained with UBALMANAC, assuming different meshes, directions of the seismic load and interconnection of the walls. $\boldsymbol{\alpha}_{0}$ is the collapse acceleration from limit analysis (normalized against $\mathrm{g}$ ) and $\boldsymbol{a}_{0}^{*}$ the corresponding spectral acceleration. 
Façade, out-of-plane, weak connect. $\quad$ Façade, out-of-plane, good connect.
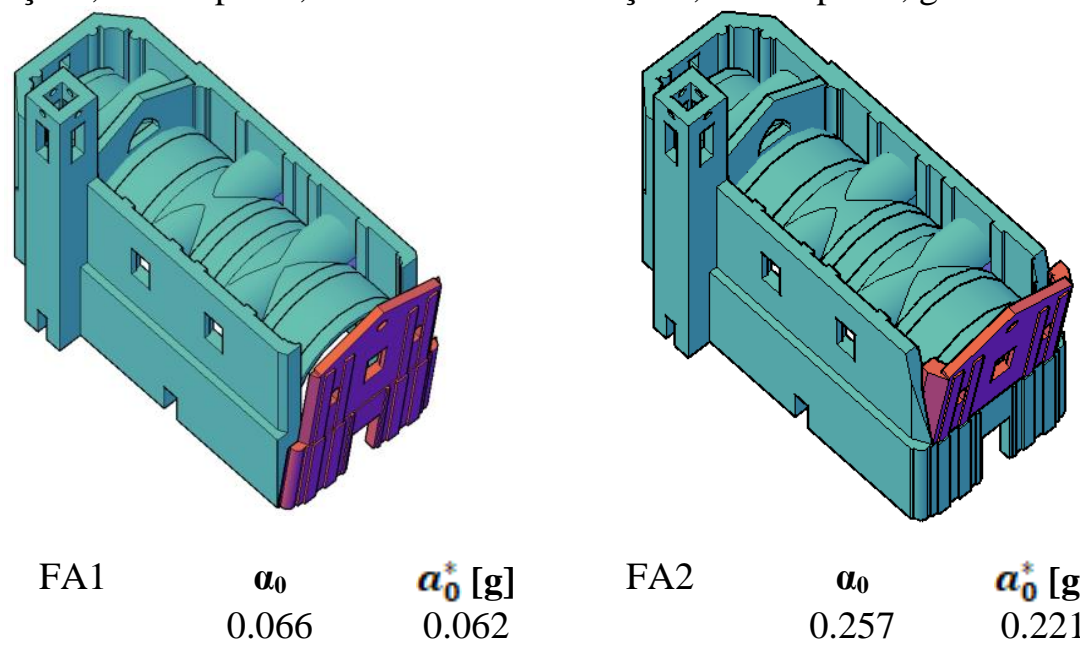

FA2
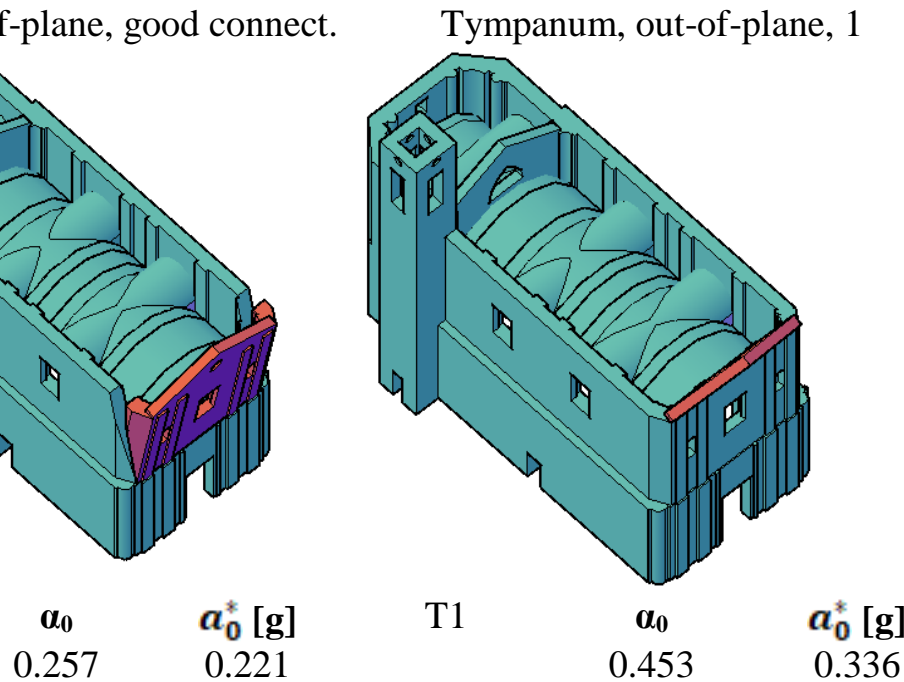

Tympanum, out-of-plane, 2

Tryumphal arch, out-of-plane

Tryumphal arch, in-plane
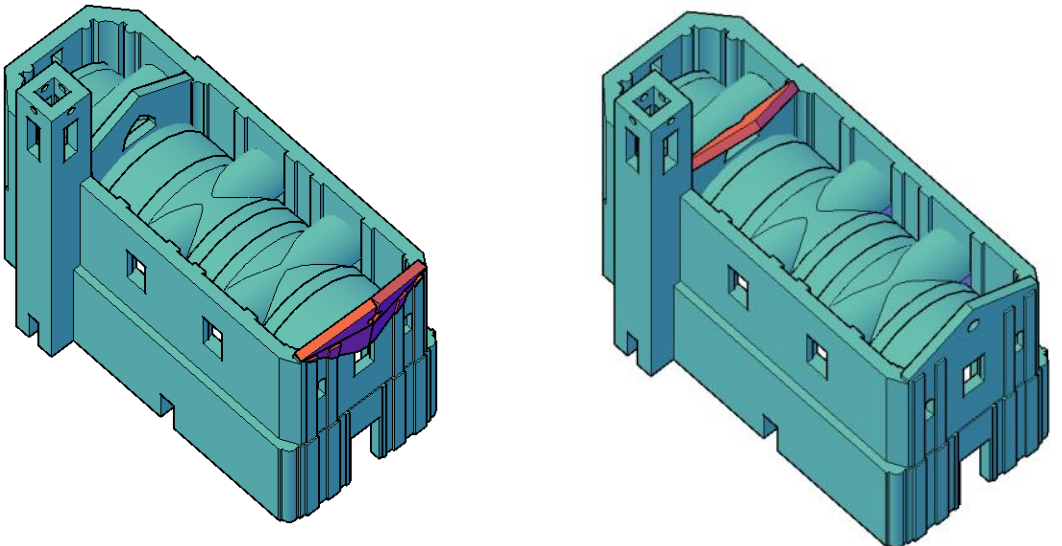

$\mathrm{T} 2$

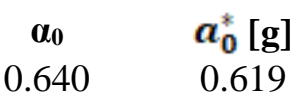

TA1

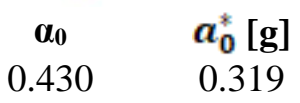

TA2

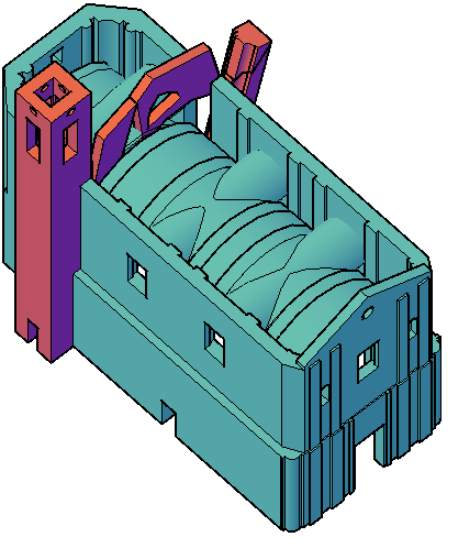

Apse, 1

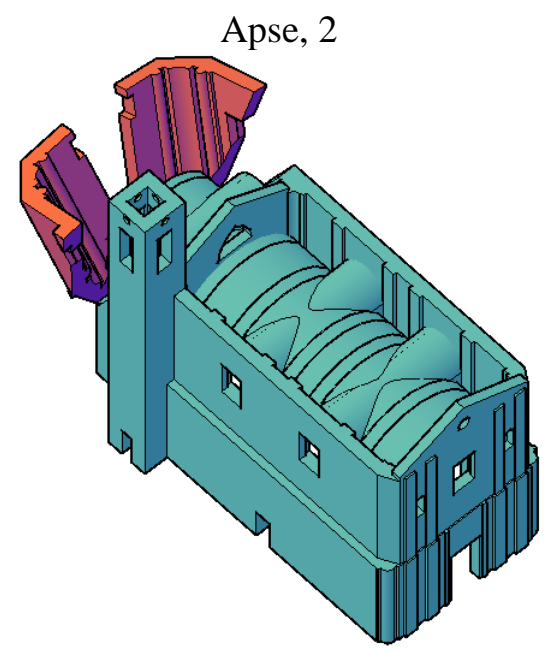

AP1

$\boldsymbol{a}_{0}^{*}[\mathrm{~g}]$

AP2
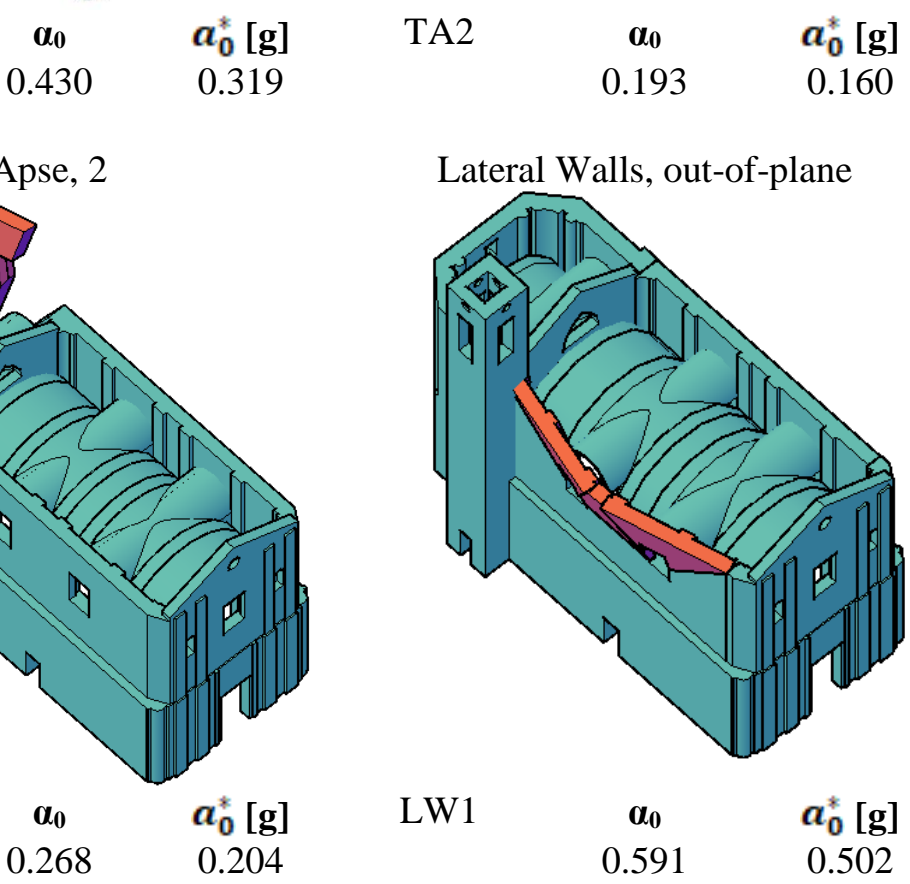

Lateral Walls, out-of-plane

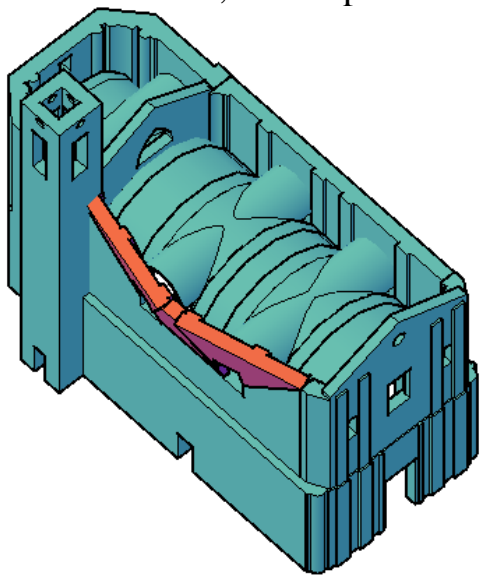

LW1

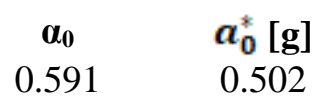

Figure 12: Church 3, Madonna della Misericordia in Petriolo. Failure mechanisms obtained with UBALMANAC assuming different meshes, directions of the seismic load and interconnection of the walls. $\alpha_{0}$ is the collapse acceleration from limit analysis (normalized against $\mathrm{g}$ ) and $\boldsymbol{a}_{0}^{*}$ the corresponding spectral acceleration. 
- Church 2: a total number of 20 NURBS surfaces and 42 elements have been defined. This church exhibits some common features at failure already found in Church 1, namely a failure of the upper part of the façade, with clear detachment from perpendicular walls, transversal rocking of the long lateral walls and apse failure (with seismic loads acting along the longitudinal positive direction), see Figure 5.

Such real crack patters seem reasonably in agreement with present code predictions (Figure 11), highlighting also a high vulnerability of the upper part of the façade, the apse and for transversal actions, of the lateral walls of the chapels for out-of-plane actions.

- Church 3: a total number of 9 NURBS surfaces and 26 elements have been defined. The crack pattern on façade, lateral wall and apse is suggestive of a failure of the church activated for transversal loads. Collapse load associated to present model findings in such case are relatively small, see Figure 12. Such an outcome could be in partial agreement with the real damages suffered by the seismic sequence.

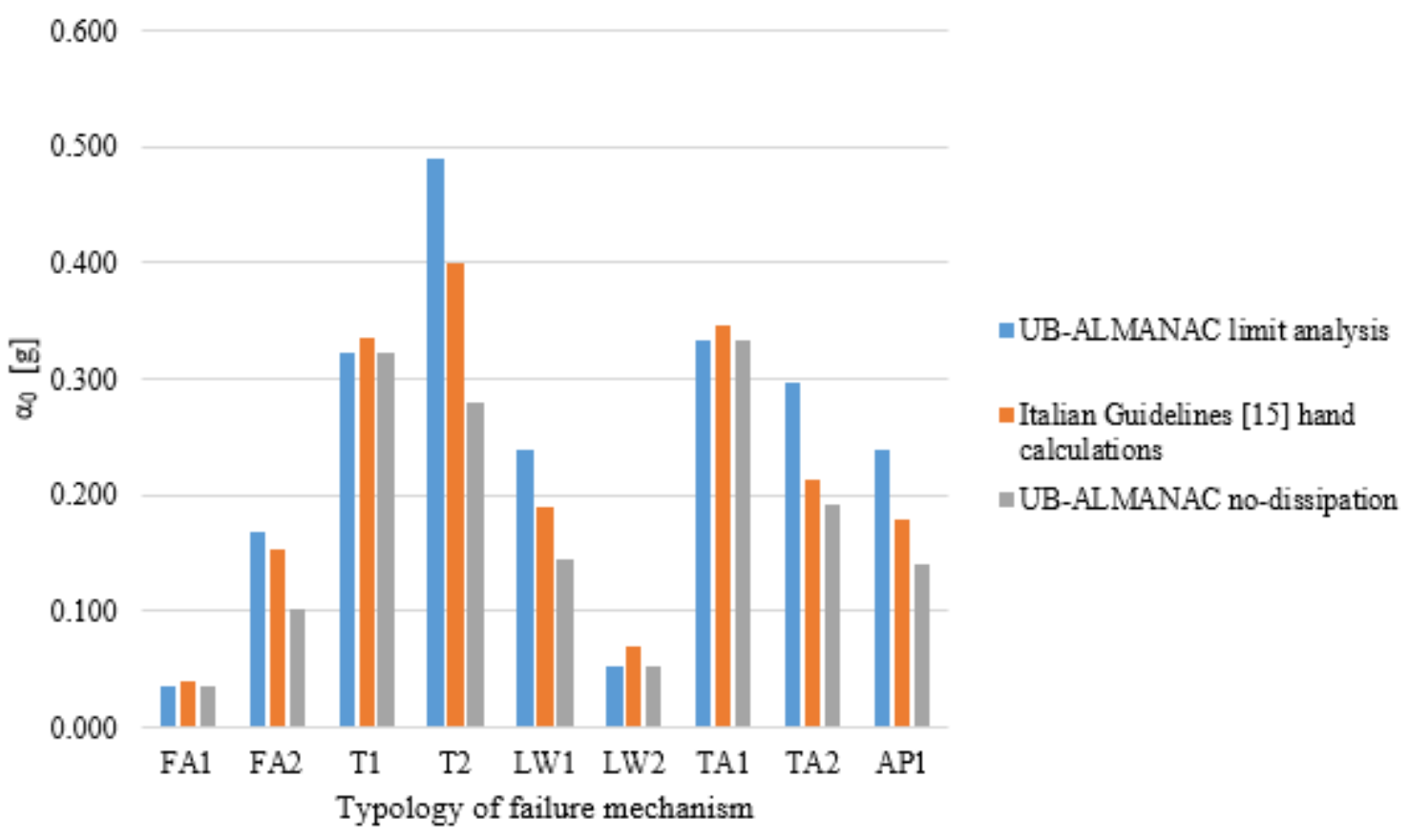

Figure 13: Church 1, San Giacomo Maggiore Apostolo in Polesine (Pegognaga). Comparison among the different failure multipliers (representing $\alpha_{0}$ ) obtained with the different approaches. Blue: UB-ALMANAC limit analysis results. Orange: Italian Guidelines [15] hand calculations. Grey: UB-ALMANAC limit analysis results with no-dissipation. 


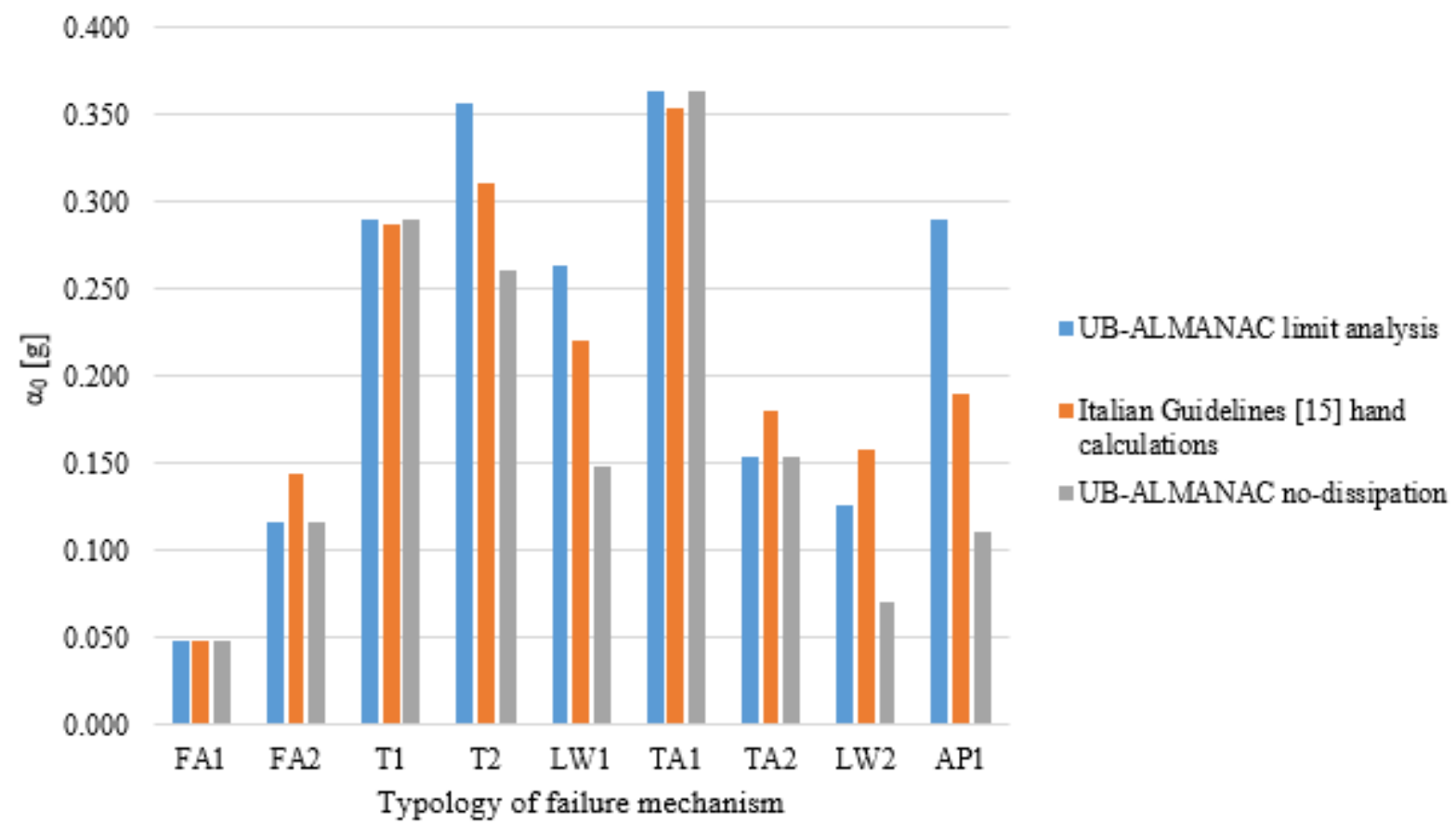

Figure 14: Church 2, Natività di Maria Vergine in Bondeno. Comparison among the different failure multipliers (representing $\alpha_{0}$ ) obtained with the different approaches. Blue: UB-ALMANAC limit analysis results. Orange: Italian Guidelines [15] hand calculations. Grey: UB-ALMANAC limit analysis results with no-dissipation.

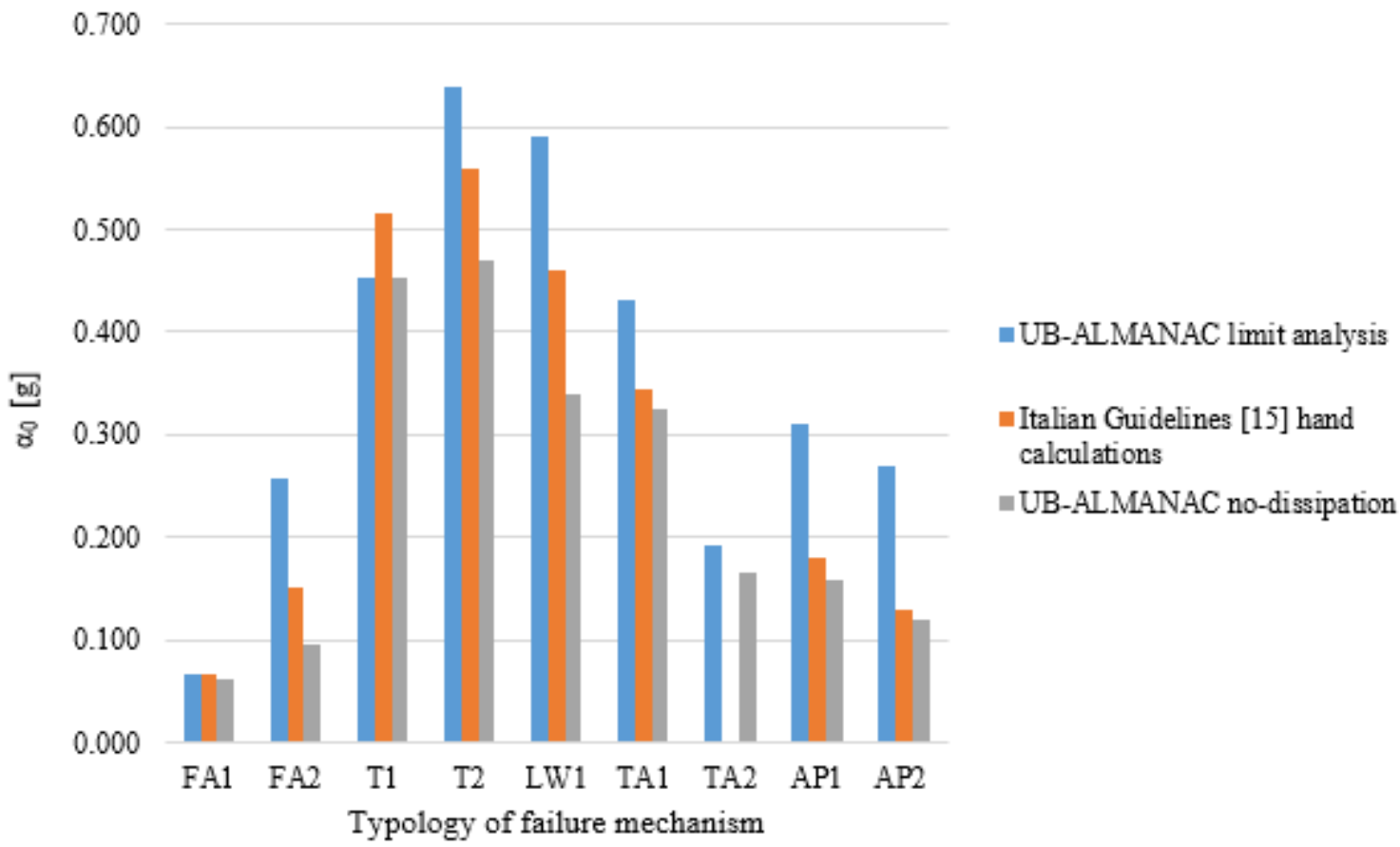

Figure 15: Church 3, Madonna della Misericordia in Petriolo. Comparison among the different failure multipliers (representing $\alpha_{0}$ ) obtained with the different approaches. Blue: UB-ALMANAC limit analysis results. Orange: Italian Guidelines [15] hand calculations. Grey: UB-ALMANAC limit analysis results with no-dissipation. 
To conclude, in general, from Figures 13-14-15 it can be seen that in many cases there is good agreement between the results automatically obtained with UB-ALMANAC and the results obtained through hand calculations following the procedures suggested by the Italian Guidelines [15] for preassigned failure mechanisms. Nevertheless, there are also few differences. It is authors' opinion that the reason, as already pointed out, lies in the fact that the mechanisms suggested in [15] are not always the actual failure mechanisms.

In addition, the choice of the interlocking level between perpendicular walls is somewhat arbitrary and turns out to be a key issue. Indeed, if neglected, it turns out to provide always very low collapse accelerations, basically linked to the inverse of the slenderness of the wall under consideration. Moreover, it should be pointed out that other differences can be a consequence of the fact that the procedure prescribed in [15] (i.e. hand calculations) totally neglects dissipation due to shear sliding between blocks and crushing of masonry, potentially leading to the identification of mechanisms that do not actually occur in reality.

Sometimes, internal dissipation due to shear, cracking and crushing may play a certain role, affecting the results. For this latter reason, Figures 13-14-15 also depict the results obtained for the mechanism automatically found by UB-ALMANAC under the hypothesis of zero dissipation on yield lines (grey bars). Results are simply obtained imposing a further equality constraint where internal dissipation is assumed vanishing. After such assumption, it is seen that the result, as expected, is generally very close to hand calculations provided by [15].

\section{Conclusions}

In this paper, an automatic computational procedure has been presented that, starting from a 3D CAD model of a church, passing through a NURBS discretization of the whole structure used as a basis for FE kinematic limit analysis computations and ending with a mesh adaptation process by means of a meta-heuristic approach (GA), is able to furnish precise information on the most vulnerable parts and realistically predicts the acceleration activating the collapse. Differently from other approaches present 
in the literature, see e.g. [32,33], the proposed tool is completely automatic and unexperienced users can benefit from it without a particular structural background. In addition, it can run both on an unrefined discretization of the whole church or on particular macro-elements or limited portions, interactively selected by the user just within the CAD environment.

The procedure has been benchmarked on three churches severely damaged by two recent Italian seismic sequences, proving to be reliable when tested against consolidated hand computations basing on limit analysis. The related advantages have been put in evidence, namely: (1) the ability to find automatically the actual failure mechanism, which is obviously hardily determined manually, especially with moderate/good interlocking on corners; (2) the easiness of utilization by unexperienced users and (3) the possibility to take into account exact geometry and loading conditions. Results provided by UB-ALMANAC realistically take into account dissipation due to shear mechanisms and masonry crushing, which are otherwise neglected by hand calculations prescribed by Italian Guidelines [15], which -as a consequence- often provide unrealistic estimates of the safety levels of macroblocks. Future developments of the program, apart its distribution under open-source licenses, include the implementation of different typologies of seismic retrofits (e.g. tie rods, FRP strips, FRCM, NSM carbon bars, etc.) and the possibility to account for different masonry textures that can be encountered in practice, with particular regard to double leaf walls [34] subjected to out-of-plane failures.

Aknowledgements. The authors conducted this research within the University Network of Seismic Engineering Laboratories - ReLUIS research program, funded by the Italian Civil Protection National Service - Research Line "Masonry Structures", WP2-WP4. The authors are grateful to Dr. Ing. Alessandro Balducci and to the municipality of Petriolo for providing valuable information on the Church of Madonna della Misericordia. The authors also thank the two anonymous reviewers for their comments and suggestions to improve our paper. 


\section{References}

[1] F. Doglioni, A. Moretti, V. Petrini, Churches and Earthquake, Edizioni LLINT (in Italian), Trieste, 1994.

[2] S. Huerta, The Analysis of Masonry Architecture: A Historical Approach, Archit. Sci. Rev. (2011). http://www.tandfonline.com/doi/abs/10.3763/asre.2008.5136?journalCode=tasr20\#.VnKV3r86i 6E (accessed December 17, 2015).

[3] G. Brandonisio, G. Lucibello, E. Mele, A. De Luca, Damage and performance evaluation of masonry churches in the 2009 L'Aquila earthquake, Eng. Fail. Anal. 34 (2013) 693-714. doi:10.1016/J.ENGFAILANAL.2013.01.021.

[4] L. Sorrentino, L. Liberatore, L.D. Decanini, D. Liberatore, The performance of churches in the 2012 Emilia earthquakes, Bull. Earthq. Eng. 12 (2014) 2299-2331. doi:10.1007/s10518-0139519-3.

[5] G. Milani, Lesson learned after the Emilia-Romagna, Italy, 20-29 May 2012 earthquakes: A limit analysis insight on three masonry churches, Eng. Fail. Anal. 34 (2013) 761-778. doi:10.1016/J.ENGFAILANAL.2013.01.001.

[6] A. Giuffrè, Safety and Preservation of Historical Centers: the Ortigia case, Laterza (in Italian), 1993.

[7] D. Theodossopoulos, B. Sinha, A review of analytical methods in the current design processes and assessment of performance of masonry structures, Constr. Build. Mater. 41 (2013) 9901001. doi:10.1016/J.CONBUILDMAT.2012.07.095.

[8] A. Mazziotti, G. Brandonisio, E. Mele, A. De Luca, Modal dynamic analysis of masonry churches, AIP Conf. Proc. 1702 (2015) 160002. doi:10.1063/1.4938928.

[9] M. Betti, A. Vignoli, Numerical assessment of the static and seismic behaviour of the basilica of Santa Maria all’Impruneta (Italy), Constr. Build. Mater. 25 (2011) 4308-4324. doi:10.1016/J.CONBUILDMAT.2010.12.028.

[10] S. Lagomarsino, S. Cattari, Seismic Performance of Historical Masonry Structures Through Pushover and Nonlinear Dynamic Analyses, in: Springer, Cham, 2015: pp. 265-292. doi:10.1007/978-3-319-16964-4_11.

[11] Y. Endo, L. Pelà, P. Roca, F. da Porto, C. Modena, Comparison of seismic analysis methods applied to a historical church struck by 2009 L'Aquila earthquake, Bull. Earthq. Eng. 13 (2015) 3749-3778. doi:10.1007/s10518-015-9796-0.

[12] M. Betti, A. Borghini, S. Boschi, A. Ciavattone, A. Vignoli, Comparative Seismic Risk Assessment of Basilica-type Churches, J. Earthq. Eng. (2017) 1-34. doi:10.1080/13632469.2017.1309602.

[13] A. Elyamani, P. Roca, O. Caselles, J. Clapes, Seismic safety assessment of historical structures using updated numerical models: The case of Mallorca cathedral in Spain, Eng. Fail. Anal. 74 (2017) 54-79. doi:10.1016/J.ENGFAILANAL.2016.12.017.

[14] S. Lagomarsino, Damage assessment of churches after L'Aquila earthquake (2009), Bull. Earthq. Eng. 10 (2012) 73-92. doi:10.1007/s10518-011-9307-x.

[15] DPCM 09/02/2011, Guidelines for the Assessment and Seismic Risk Reduction of Cultural Heritage with Reference to D.M. 14/01/2008, Gazzetta Ufficiale della Repubblica Italiana n.47 del 26/02/2011, in Italian, (2011). 
[16] J. Heyman, The stone skeleton : structural engineering of masonry architecture, Cambridge University Press, 1995.

[17] M. Como, Statics of Historic Masonry Constructions, Springer Berlin Heidelberg, Berlin, Heidelberg, 2013. doi:10.1007/978-3-642-30132-2.

[18] A. Kooharian, Limit Analysis of Voussoir (Segmental) and Concrete Archs, ACI J. Proc. 49 (1952). doi:10.14359/11822.

[19] M. Dhanasekar, A.W. Page, P.W. Kleeman, The Failure of Brick Masonry Under Biaxial Stresses, Proc. Inst. Civ. Eng. 79 (1985) 295-313. doi:10.1680/iicep.1985.992.

[20] A. Chiozzi, G. Milani, A. Tralli, A Genetic Algorithm NURBS-based new approach for fast kinematic limit analysis of masonry vaults, Comput. Struct. 182 (2017) 187-204. doi:10.1016/j.compstruc.2016.11.003.

[21] A. Chiozzi, G. Milani, N. Grillanda, A. Tralli, A fast and general upper-bound limit analysis approach for out-of-plane loaded masonry walls, Meccanica. (2017) 1-24. doi:10.1007/s11012017-0637-x.

[22] A. Chiozzi, G. Milani, A. Tralli, Fast Kinematic Limit Analysis of FRP-Reinforced Masonry Vaults. I: A General Genetic Algorithm NURBS-based Formulation, J. Eng. Mech. 143 (2017). doi:10.1061/(ASCE)EM.1943-7889.0001267.

[23] A. Chiozzi, G. Milani, A. Tralli, Fast Kinematic Limit Analysis of FRP-Reinforced Masonry Vaults. II: Numerical Simulations, J. Eng. Mech. 143 (2017). doi:10.1061/(ASCE)EM.19437889.0001268 .

[24] E. Milani, G. Milani, A. Tralli, Limit analysis of masonry vaults by means of curved shell finite elements and homogenization, Int. J. Solids Struct. 45 (2008) 5258-5288. doi:10.1016/j.ijsolstr.2008.05.019.

[25] G. Milani, A. Taliercio, In-plane failure surfaces for masonry with joints of finite thickness estimated by a Method of Cells-type approach, Comput. Struct. 150 (2015) 34-51. doi:10.1016/j.compstruc.2014.12.007.

[26] R.L. Haupt, S.E. Haupt, Practical Genetic Algorithms, John Wiley \& Sons, 2004. https://books.google.com/books?id=k0jFfsmbtZIC\&pgis=1 (accessed December 17, 2015).

[27] L. Piegl, W. Tiller, The NURBS Book, Springer Berlin Heidelberg, Berlin, Heidelberg, 1995. doi:10.1007/978-3-642-97385-7.

[28] G. Milani, P.B. Lourenço, A. Tralli, Homogenised limit analysis of masonry walls, Part I: Failure surfaces, Comput. Struct. 84 (2006) 166-180. doi:10.1016/j.compstruc.2005.09.005.

[29] G. Milani, S. Casolo, A. Naliato, A. Tralli, Seismic Assessment of a Medieval Masonry Tower in Northern Italy by Limit, Nonlinear Static, and Full Dynamic Analyses, Int. J. Archit. Herit. 6 (2012) 489-524. doi:10.1080/15583058.2011.588987.

[30] Circolare del Ministero dei Lavori Pubblici n. 617 del 2/2/2009, Instructions for the application of the new Italian Buildiong Code with Reference to D.M. 14/01/2008, Gazzetta Ufficiale della Repubblica Italiana n. 47 del 26/02/2009, in Italian, (2009).

[31] Decreto Ministeriale 14/01/2008, New Italian Building Code, Gazzetta Ufficiale della Repubblica Italiana n. 29 del 04/02/1008, in Italian, (2008).

[32] A. Tralli, C. Alessandri, G. Milani, Computational Methods for Masonry Vaults: A Review of Recent Results, Open Civ. Eng. J. 8 (2014). http://benthamopen.com/ABSTRACT/TOCIEJ-8272 (accessed December 17, 2015).

[33] E. Reccia, A. Cazzani, A. Cecchi, FEM-DEM Modeling for Out-of-plane Loaded Masonry 
Panels: A Limit Analysis Approach, Open Civ. Eng. J. 6 (2012) 231-238.

doi:10.2174/1874149501206010231.

[34] I. Aldreghetti, D. Baraldi, G. Boscato, A. Cecchi, L. Massaria, M. Pavlovic, E. Reccia, I.

Tofani, Multi-Leaf Masonry Walls with Full, Damaged and Consolidated Infill: Experimental and Numerical Analyses, Key Eng. Mater. 747 (2017) 488-495.

doi:10.4028/www.scientific.net/KEM.747.488. 